\title{
Happiness Goal Orientations and their Associations with Well-Being
}

\author{
Julia Krasko ${ }^{1}$, Vera M. Schweitzer ${ }^{2}$, and Maike Luhmann ${ }^{1}$ \\ ${ }^{1}$ Ruhr University Bochum, Faculty of Psychology, Germany \\ ${ }^{2}$ WHU - Otto Beisheim School of Management, Düsseldorf, Germany
}

\section{Note}

This is the final accepted version, November 25, 2020 (Journal of Well-Being Assessment). This postprint may differ slightly from the final, copy-edited version of this article. https://doi.org/10.1007/s41543-020-00029-x

Correspondence regarding this article should be addressed to Julia Krasko, Ruhr University Bochum, Universitätsstrasse 150, 44801 Bochum, Germany, e-mail:

julia.krasko@rub.de. Preparation of this manuscript was supported by grant \#57313 awarded to Maike Luhmann by the Happiness \& Well-Being Project, a joint program by the St. Louis University and the Templeton Foundation. We would like to thank Vivien Janowicz, Markus Krause, and Marie von Rogal for their help with this manuscript. 


\begin{abstract}
Previous research has provided contradicting findings on whether valuing and pursuing happiness is beneficial or detrimental to one's level of well-being. These contradicting findings might be resolved by considering these so-called Happiness Goal Orientations (HGO) as a multidimensional construct. The goals of this paper were (1) to present a new multidimensional scale to measure HGO and (2) to investigate whether the different dimensions of the scale are differentially related to well-being. Inspired by theories that distinguish between different dimensions of motivational systems and goal pursuit, we developed and validated the HGO Scale in four independent studies. The scale distinguishes two dimensions: Happiness-Related Strivings represent the propensity to move actively and persistently toward the desired level of happiness. Happiness-Related Concerns represent the propensity to worry about and to focus on threats to one's level of happiness. HappinessRelated Strivings are associated with approach-related constructs, positivity, successful strategies to regulate one's moods and emotions, endorsing a broad range of happiness definitions, and the intention to pursue different happiness definitions in everyday life. Happiness-Related Concerns are associated with avoidance-related constructs, anxiety, poor strategies to regulate one's moods and emotions, defining happiness solely as the absence of negativity, and having no intentions to pursue happiness in everyday life. Happiness-Related Strivings are positively associated with well-being, whereas Happiness-Related Concerns are negatively associated with well-being. These differential associations with well-being demonstrate the importance of considering $\mathrm{HGO}$ as a multidimensional construct and that HGO can be both beneficial and detrimental to one's level of well-being.
\end{abstract}

Keywords: happiness, subjective well-being, psychological well-being, scale development, pursuit of happiness, lay definitions of happiness 


\section{Introduction}

Most people want to attain and maintain happiness (Diener et al., 1998; King \& Napa, 1998). But how does this pervasive desire for happiness affect the actual level of well-being? Whether valuing and pursuing happiness is advantageous or detrimental for well-being is controversial (Catalino et al., 2014; Gruber et al., 2011; Luhmann et al., 2016). On the one hand, it is a widespread view among scholars (Martin, 2008; McGuirk et al., 2018) and lay people (Joshanloo \& Weijers, 2013) that the Western "cultural obsession” (McGuirk, Kuppens, Kingston, \& Bastian, 2018, p. 755) with happiness leads to paradoxical effects and might be self-defeating (Martin, 2008; Mauss et al., 2011; McGuirk et al., 2018). Indeed, a negative link between valuing and pursuing happiness and actual levels of well-being has been found in cross-sectional (Ford, Mauss, et al., 2015; Gentzler et al., 2019) and experimental studies (Mauss et al., 2011; McGuirk et al., 2018; Schooler et al., 2003).

On the other hand, some scholars suggest that "our obsession is well justified" (Steel, Taras, Uggerslev, \& Bosco, 2018, p. 128) because efforts to become happy bring one closer to the desired goal. For example, being guided by potential positive emotional experiences is a positive correlate (Catalino et al., 2014; Peterson et al., 2005) and a longitudinal predictor (Datu \& King, 2016) of well-being. Efforts to increase happiness through interventions and activities also demonstrate that it pays off to work actively to improve one's level of wellbeing (Bolier et al., 2013; Sin \& Lyubomirsky, 2009).

Are these opposing associations between valuing and pursuing happiness and actual levels of well-being incompatible? A closer examination of the literature reveals that negative associations were particularly found in studies where valuing and pursuing happiness was characterized by the fear of and desire to avoid negative emotions (Luhmann et al., 2016; Luong et al., 2016), for example due to low expectancies to regulate one's mood (Fergus \& Bardeen, 2016) or the perceived social pressure not to be unhappy (McGuirk et al., 2018). 
The desire for positive affect, however, was either not significantly or positively related to well-being (Catalino et al., 2014; Luhmann et al., 2016; Luong et al., 2016; Peterson et al., 2005). Consequently, valuing and pursuing happiness might be neither advantageous nor detrimental to experienced happiness per se.

In this article, we propose that these discrepant findings can be reconciled by considering valuing and pursuing happiness as a multidimensional construct, which we label as Happiness Goal Orientations (HGO). For a range of psychological constructs, a multidimensional consideration revealed that associations between these constructs and other variables such as well-being differed among different dimensions of these constructs (Briki, 2018; Churchyard \& Buchanan, 2017; Elliot \& Thrash, 2002; George \& Park, 2017; Gross \& John, 2003; Koole \& Jostmann, 2004; Stoeber \& Otto, 2006). Some psychological constructs were initially considered to be unidimensional, and a multidimensional perspective was introduced only later in the research process. For example, distinguishing the dimensions admiration and rivalry of grandiose narcissism revealed distinct processes (Back et al., 2013). Similarly, the distinction between perfectionistic concerns and perfectionistic strivings was introduced after perfectionism was considered as a merely dysfunctional unidimensional construct (Stoeber \& Otto, 2006; Stricker et al., 2019). Recently, a multidimensional perspective of meaning was introduced that distinguished between comprehension, purpose, and mattering (George \& Park, 2017). Applying a multidimensional perspective helped to resolve conceptual difficulties and contradicting findings in the literature, and revealed differential nomological networks, interpersonal consequences, and associations with other variables (Back et al., 2013; George \& Park, 2017; Stoeber \& Otto, 2006; Stricker et al., 2019).

In the present paper, we examined whether adopting a multidimensional perspective may also resolve contradicting findings on the relationship between valuing and pursuing 
happiness and actual levels of well-being. A study by Luhmann et al. (2016) supports this assumption: The unidimensional structure of the HGO-related Valuing Happiness Scale (Mauss et al., 2011) led to constrained conclusions regarding the associations with wellbeing, whereas a multidimensional consideration of this relation revealed differential associations between facets of this scale and well-being. As we elaborate below, existing measures of HGO-related constructs (e.g., Bastian et al., 2012; Catalino et al., 2014; Mauss et al., 2011) are inadequate to measure different dimensions of HGO. The first goal of this article was therefore to close this research gap by presenting a new multidimensional scale to measure HGO. In four independent studies, we developed the Happiness Goal Orientations Scale, which distinguishes the two dimensions Happiness-Related Strivings and HappinessRelated Concerns, and provide evidence for its construct validity. The second goal of this article was to investigate whether the two dimensions are differentially related to well-being, which may explain previous discrepant findings on the relationship between valuing and pursuing happiness and well-being.

\subsection{Measuring Happiness Goal Orientations}

People differ in how they value and pursue happiness regarding the specific definitions of happiness they endorse (Joshanloo, 2019; Kämpfe \& Mitte, 2009; McMahan \& Estes, 2011; Peterson et al., 2005) as well as regarding motivations, emotions, cognitions, and behaviors toward happiness as a desired goal (Catalino et al., 2014; Fergus \& Bardeen, 2016; Luhmann et al., 2016; Luong et al., 2016). In this paper, we focus on the latter and are particularly interested in individual differences in orientations toward happiness as a desired goal. We were inspired by theories that consider different dimensions of motivational systems and goal pursuit for scale development (Carver \& White, 1994; Elliot \& Thrash, 2002; Gray, 1990; Higgins, 1997; Kuhl, 2000). 
For example, Gray's (1990) Reinforcement Sensitivity Theory proposed two systems that underlie behavior and affect by reacting to different types of stimuli and generating different goal-related outcomes. The behavioral activation system (BAS) reacts sensitively to signals of reward and non-punishment and leads to approach behavior as well as to an increase of attention toward the rewarding stimuli. The behavioral inhibition system (BIS) reacts sensitively to signals of innate fear stimuli and punishment and leads to the inhibition of behavior as well as to an increase of attention toward the threatening stimuli. Several scales were developed to measure differences in reinforcement sensitivity (Carver \& White, 1994; Corr \& Cooper, 2016; Hartig \& Moosbrugger, 2003; Smederevac et al., 2014). These scales usually comprise several subscales of BAS and BIS that vary regarding the specific content. Most commonly, BAS scales measure the tendency to resist setbacks and to make a great effort to reach a desired goal (Carver \& White, 1994; Corr \& Cooper, 2016; Hartig \& Moosbrugger, 2003). Some BAS subscales also refer to positive emotional responsiveness to the anticipation or actual occurrence of rewards or successes (Carver \& White, 1994; Hartig \& Moosbrugger, 2003), interest and a general desire for novel or fun experiences (Carver \& White, 1994; Corr \& Cooper, 2016), or a strategic approach to reach desired goals (Corr \& Cooper, 2016). BIS scales most commonly focus on worries and anxiety by referring to cognitions and emotional reactions to the anticipation or actual occurrence of negative experiences like punishment or negative reactions of others (Carver \& White, 1994; Corr \& Cooper, 2016; Hartig \& Moosbrugger, 2003). Some BIS scales also refer to emotional reactions like frustration and disappointment as a consequence of the occurrence of failures (Hartig \& Moosbrugger, 2003), or to the active avoidance and withdrawal as a consequence of the desire to avoid potential negative experiences (Corr \& Cooper, 2016). Other examples of theories related to goal pursuit include the Action-Control Theory (Kuhl, 1984, 2000). This theory explains individual differences in attention control, motivation control, emotion 
control, and coping with failure in the context of goal pursuit and distinguishes between action orientation and state orientation. Action orientation refers to the tendency to act quickly, to approach goals actively, to invest resources in order to implement desired outcomes, and to maintain goal-serving emotions, cognitions, and motivations. State orientation refers to the tendency to ruminate and hesitate, a lack of energy to initiate or maintain intended behavior, and a false internalization of others' beliefs and expectations (Kuhl, 1984, 2000). Higgins' (1997) Regulatory Focus Theory distinguishes a promotion and a prevention focus. The former describes a focus on accomplishments and aspirations by envisioning and pursuing desirable outcomes, whereas the latter describes a focus on safety and responsibilities by worrying about and avoiding undesirable outcomes (Higgins, 1997; Lockwood et al., 2002).

In sum, these theories describe individual differences in the pursuit of goals in life. In this paper, we aimed to investigate whether a multidimensional approach can be applied to HGO, namely goal orientations with regard to attaining or maintaining a sufficient level of happiness in life. Further, in the above-described theories, goal-related motivations and cognitions are closely linked to specific emotional states and anticipated behavior. Since emotions and cognitions overlap in motivational systems, it is difficult to distinguish between these units of experience (Gray, 1990). In line with the above-described theories, we aimed to capture a wide range of goal-related experiences and thus to measure emotions, cognitions, and anticipated behavior toward happiness as a desired goal.

Although several measures of HGO and related constructs exist (e.g., Bastian et al., 2012; Catalino et al., 2014; Joshanloo, 2013; Mauss et al., 2011; McMahan \& Estes, 2011; Peterson et al., 2005), some of them fail to take a potential multidimensional structure into account and only include items that focus on one specific aspect of the construct. For example, the Prioritizing Positivity scale only measures to what extent people focus on 
increasing and maintaining positive aspects in life by orienting their everyday decisions toward a potential happiness gain (Catalino et al., 2014). The Fear of Happiness scale only focuses on the belief that the experience of happiness might have negative consequences (Joshanloo, 2013). Some scales assess whether people believe that happiness is fixed and depends on external factors or whether happiness is changeable and can be actively affected (Howell et al., 2016; Joshanloo, 2017, 2019). Although the Valuing Happiness scale (Mauss et al., 2011) appears to assess different aspects like the personal importance of being happy and worries about the possibility of being unhappy (Luhmann et al., 2016), the scale was constructed as a unidimensional measure and does not provide enough items to distinguish between different dimensions reliably. Further, the Valuing Happiness scale only assesses individual differences in the importance of happiness and not the extent to which people pursue happiness-related goals. This distinction is crucial, as general values and motivations do not automatically result in specific goals and actions required to realize the desired outcomes (Gollwitzer \& Sheeran, 2006; Hsee \& Hastie, 2006; Oettingen et al., 2001). Hence, goal orientations are a more proximal predictor of actual well-being than general values, which is why we focus on the former.

Furthermore, existing HGO-related multidimensional scales do not capture differences in goal orientations. Instead, these scales distinguish among different definitions of happiness (Krasko et al., 2020; McMahan \& Estes, 2011; Peterson et al., 2005). For example, the Beliefs About Well-Being scale (McMahan \& Estes, 2011) assesses to what extend people consider the dimensions experience of pleasure, avoidance of negative experience, self-development, and contribution to others as required aspects of the experience of high well-being. However, the scale does not assess the extent to which people pursue these different definitions of happiness in their lives. The HGO-related multidimensional scale of Bastian et al. (2012) distinguishes between personal and social expectations with a 
focus on experienced negative emotions only (Bastian et al., 2012). Because of these limitations of existing measures of HGO-related constructs, we developed a new multidimensional scale that measures individual differences in orientations toward happiness goals.

\subsection{Investigating Different Types of Well-Being}

Well-being is a multifaceted construct encompassing constructs such as subjective well-being (SWB) and psychological well-being (PWB; Disabato, Goodman, Kashdan, Short, \& Jarden, 2016; Henderson \& Knight, 2012; Huta \& Ryan, 2010). SWB includes positive and negative affective experiences and subjective evaluations of one's life satisfaction (Diener, 1984). In contrast, PWB comprises different facets of positive psychological functioning such as positive relations with others or self-acceptance (Ryff, 1989). SWB and PWB are related but distinct and vary in their relations with other constructs (Keyes et al., 2002; Linley et al., 2009).

To investigate whether the two types of well-being are differentially associated with HGO, we will examine both SWB and PWB as outcome variables. Previous research on the relation between HGO-related constructs and well-being mostly focused on SWB as the outcome variable. For this reason, our investigation of whether the same relations with HGO can be observed when examining PWB as an alternative type of well-being is rather exploratory. However, Mauss et al. (2011) examined both types of well-being and showed that SWB and PWB correlate with the Valuing Happiness Scale in a similar fashion. Based on this result and due to the interrelations of SWB and PWB (Keyes et al., 2002; Linley et al., 2009), we expected that SWB and PWB would be associated with HGO in the same direction. 


\subsection{The Present Paper}

The first aim of this paper was to develop a short multidimensional measure of HGO (Study 1, Study 2a \& 2b) and to provide evidence for its construct validity (Study 2a \& Study 3). The second aim was to examine the associations between HGO and well-being, by considering SWB (Diener, 1984; Study 2a \& 2b, Study 3) and PWB (Ryff, 1989; Study 2b \& Study 3). To ensure that associations between HGO and well-being do not simply reflect demographical differences, we controlled for age and gender. Further, to ensure that these associations do not simply reflect more general personality traits, we conducted all analyses with and without controlling for extraversion and neuroticism.

\section{Study 1}

The main objective of Study 1 was to create a measure that allows a multidimensional assessment of HGO. The scale development was inspired by theories of motivational systems and goal pursuit.

\subsection{Methods}

\subsubsection{Participants and Procedure}

Data collection was conducted in Summer 2016 using the online survey tool Qualtrics. Participants were recruited through different online sources (e.g., mailing lists, Facebook groups) that particularly address German students. All participants could participate in a lottery of two Amazon vouchers worth $25 €$. Informed consent was obtained from all individual participants included in the study. We first presented items for HGO in a randomized order, followed by demographic questions. We collected responses from 296 participants, which were reduced by 76 incomplete cases and three cases with inadequate responses to an item for the self-assessment of data quality (see below). The final sample size was $N=217$, which is appropriate for the ratio of assessed variables to expected factors in 
this study (MacCallum et al., 1999). Age ranged from 19 to $57(M=24.43, S D=4.78)$, $76.0 \%$ of the sample was female, $95.9 \%$ not married, $60.8 \%$ in a romantic relationship, $89.9 \%$ indicated to have a general higher education entrance qualification (Abitur), $85.7 \%$ indicated to have a current student status, $8.3 \%$ were employed.

\subsubsection{Measures}

For item development, we used existing scales of constructs related to motivational systems and goal pursuit (e.g., BIS/BAS; Carver \& White, 1994) as well as scales that focus on attitudes and emotional reactions to happiness (e.g., Orientations to Happiness; Peterson et al., 2005). We selected suitable items and adopted the wording for our purpose. An initial pool of 77 items was reduced after discussion among the authors and by dropping redundant items, which resulted in 27 items for assessment. Participants were asked to indicate to what extent they agree with the statements on a scale from 1 (does not apply) to 5 (applies completely).

To control for data quality, we included one dichotomous item for self-assessment of data quality (i.e., directly asking whether the participants answered the survey questions appropriately). Additionally, we assessed basic demographics such as age and gender.

\subsection{Results}

All analyses were conducted in the R environment (R Development Core Team, 2008) using the packages psych (Revelle, 2017) and QuantPsych (Fletcher, 2012) ${ }^{1}$. In a first step, we excluded poorly performing items as indicated by established psychometric criteria, like

\footnotetext{
${ }^{1}$ To reproduce our results, all data files and R-codes can be found online: https://osf.io/dg83m/?view_only=08b08fa372ee4f60b923cd2b5046cb32
} 
moderate item difficulties (Lord, 1952; optimally between $2.5-3.5$ on a $1-5$ scale), high discriminatory power (Jackson, 1970; optimally > .35), skewness and kurtosis (optimally no significant deviation above $|1.5|$ from 0 ), and visual inspection of response distributions (optimally normally distributed ${ }^{2}$ ). We kept the best performing items for the next step and omitted 13 items that performed worse on these criteria (i.e., all of these excluded items performed poorly on at least two criteria). For the remaining 14 items, we conducted an exploratory factor analysis to examine the dimensionality of the scale (for an overview of the psychometric properties of the items, see Table 1). We determined the number of factors using parallel analysis (Goretzko et al., 2019; Horn, 1965) as implemented in the R package psych (Revelle, 2017). In this package, parallel analysis is performed using both principal axis factor analysis and principal component analysis. For principal axis factor analysis, parallel analysis suggested three factors: The first five observed eigenvalues were 3.45, 1.48, $0.44,0.16,0.04$ and the first five simulated eigenvalues were $0.68,0.36,0.28,0.21,0.16$. For the principal component analysis, parallel analysis suggested two components: The first five observed eigenvalues were 4.13, 2.30, 1.14, 0.96, 0.84 and the first five simulated eigenvalues were $1.45,1.33,1.25,1.18,1.12$. The application of other criteria (scree test and Kaiser-Criterion) did not clarify whether two or three factors are more appropriate. For this reason, we decided to consider both solutions for the next steps. We estimated one model with two factors and another model with three factors using principal axis analysis, Promax Rotation, and Maximum Likelihood (ML) estimation. For an overview of factor loadings, interfactor correlations, and explained variances for both factor solutions, see Table 2.

To interpret the factors, we considered items with a minimum loading of .30, which is an appropriate cutoff criterion for this sample size (Field et al., 2012; Stevens, 2002). In both

\footnotetext{
${ }^{2}$ Figures of the item distributions can be found in the online materials: https://osf.io/dg83m/?view_only=485d5346d5904c90ba3fd21614bd1860
} 
models, the factors could be interpreted meaningfully. In the two-factor solution, the first factor referred to anxiety and worries of being unhappy and a focus on threats to one's level of happiness (e.g., "I often refrain from doing something because I am scared that it might make me unhappy"). The second factor referred to goals, efforts, and activities to increase happiness or prevent unhappiness (e.g., "I try very hard to be happy"). The total explained variance was $R^{2}=.37$ for this model. Cronbach's alpha was $\alpha=.81$ for the subscale with a focus on threats, which could be improved by the removal of Item $10\left(\alpha_{\mathrm{diff}}=.01\right)$. For the subscale with a focus on activity, Cronbach's alpha was $\alpha=.74$. In the three-factor solution, the first factor referred to anxiety and worries of being unhappy. The second factor referred to goals, efforts, and activities to increase happiness or prevent unhappiness. The third factor emphasized a focus on threats to one's level of happiness, but - in contrast to the first factor without the feelings of anxiety or worries (e.g., "I focus more on threats than on pleasant events"). The total explained variance was $R^{2}=.43$. Cronbach's alpha for the subscales ranged between $\alpha=.68$ (Factor 3 ) and $\alpha=.80$ (Factor 1 ). We removed Item 10 because of weak loadings and an increased Cronbach's alpha for the two-factor solution after dropping this item, resulting in an item pool of 13 items for the next study.

\subsection{Discussion}

The main purpose of Study 1 was to develop and evaluate a multidimensional scale to measure HGO. The results suggested two potentially fitting factor solutions that were both appropriate with respect to psychometric quality and theoretical meaningfulness.

In both factor solutions, one factor emerged that was related to efforts and activities people are willing to undergo to be happy or to avoid being unhappy. This factor reflects intentions and persistence toward pursued happiness-related goals. In the two-factor solution, the second factor reflected anxiety, worries, and a focus on threats to one's level of 
happiness. In the three-factor solution, items reflecting anxiety, worries, and threats split into two different factors: One of them referred to feelings of worries and anxiety, whereas the other one referred to the focus on threats without emphasizing negative feelings.

Some indicators suggested that the two-factor model should be preferred. First, enough items are available for a reliable assessment of each factor, which could be critical for the three-factor solution. Second, in the three-factor model, one of the factors might be redundant as the correlation of $r=.55$ between two factors reflecting either feelings of worries and anxiety or a focus on threats is relatively strong. Despite these arguments for the two-factor solution, we will base the final decision on the results of confirmatory factor analyses in the following studies.

\section{Studies $2 a$ and $2 b$}

The main goal of Studies $2 \mathrm{a}$ and $2 \mathrm{~b}$ was to conduct confirmatory factor analyses to investigate the best factor solution of the HGO Scale and to improve the scale. Since the results of two independent samples were considered simultaneously for this purpose, Study $2 \mathrm{a}$ and $2 \mathrm{~b}$ will both be described in this section.

Another goal was to investigate the nomological network and the construct validity of HGO (Study 2a). For this, we expected the HGO dimension representing intentions and persistence toward pursued happiness-related goals to correlate positively with approachrelated constructs and positivity (e.g., Prioritizing Positivity, extraversion, BAS, promotion focus) and negatively with avoidance-related constructs and anxiety (e.g., neuroticism, BIS, prevention focus). For the HGO dimensions representing anxiety, worries, and a focus on threats to one's level of happiness, we expected associations in the opposite direction.

To provide further evidence of construct validity and the importance of a multidimensional consideration, we also investigated relations between $\mathrm{HGO}$ with mood 
regulation and emotion regulation strategies. Descriptions of HGO-related constructs have previously been connected to emotion regulation strategies (Luong et al., 2016). Further, the inability to successfully regulate one's mood or emotions affects the link between HGOrelated constructs and well-being negatively (Fergus \& Bardeen, 2016). Therefore, we expected the HGO dimension representing intentions and persistence toward pursued happiness-related goals to correlate positively with successful mood and emotion regulation strategies, and negatively with poor mood and emotion regulation strategies. For the HGO dimensions representing anxiety, worries, and a focus on threats to one's level of happiness, we expected negative correlations with successful mood and emotion regulation strategies, and positive correlations with poor mood and emotion regulation strategies. We also investigated perceived expectancies to feel happiness (Bastian et al., 2012), namely scales for self-evaluation, personal expectancies, and social expectancies. Social expectancies might induce pressure to not display unhappiness and the fear of not being happy enough (Bastian et al., 2012; McGuirk et al., 2018). Therefore, we expected a positive association between the HGO dimensions representing anxiety, worries, and a focus on threats to one's level of happiness, and perceived social expectancies to feel happy.

Further, we investigated the association between HGO with SWB (Study 2a \& 2b) and PWB (Study 2b), controlling for age and gender. In accordance with previous results (Bastian et al., 2012; Catalino et al., 2014; Luhmann et al., 2016; Mauss et al., 2011), we expected the HGO dimension representing intentions and persistence toward pursued happiness-related goals to be positively related to both types of well-being. For the HGO dimensions representing anxiety, worries, and a focus on threats to one's level of happiness, we expected associations in the opposite direction. Since constructs of interest in this study are correlated with extraversion and neuroticism (Agbo \& Ngwu, 2017; Pollock et al., 2016; Schimmack, Radhakrishnan, et al., 2002; Schmutte \& Ryff, 1997; Soto, 2015; Tamir, 2009; 
Tkach \& Lyubomirsky, 2006), we conducted these analyses with and without controlling for extraversion and neuroticism to ensure that associations do not simply reflect more general personality traits. We expected that associations between $\mathrm{HGO}$ and well-being would decrease but remain significantly different from zero when controlling for extraversion and neuroticism.

\subsection{Methods}

\subsubsection{Participants and Procedure}

For both studies, we used the online survey software Qualtrics. For Study 2a, data was collected in Fall 2016. Participants were recruited through different German online sources (e.g., mailing lists, Facebook groups). We avoided sources that particularly address students and had already been used for Study 1. All participants could participate in a lottery of Amazon vouchers worth $400 €$ in total. Informed consent was obtained from all individual participants included in the study. First, different scales were presented in a randomized order. Items within the scales were also randomized. At the end of the survey, we presented some basic demographic questions. Although 912 participants started the survey, we removed 415 participants which mostly did not provide any data due to unfavorable responses at the beginning on questions regarding age verification, consent, and gender ${ }^{3}$. We excluded nine cases on basis of an item for the self-assessment of data quality, 23 cases due to missing values or failed responses to two instructed response items (see below), and three cases due to missing values on HGO items. After these exclusions, the final sample size was $N=462$, which is appropriate for stable estimates of correlations (Schönbrodt \& Perugini, 2013) and the conduction of confirmatory factor analyses (Barrett, 2007; Wolf et al., 2013). The age

\footnotetext{
${ }^{3}$ After data collection was already progressed, female participants were no longer eligible to participate
} to assure a reasonable number of male participants. 
ranged from 16 to $72(M=29.54, S D=10.09), 72.1 \%$ of the sample was female, $77.3 \%$ not married, $68.6 \%$ in a romantic relationship, $65.7 \%$ indicated to have a general higher education entrance qualification (Abitur), 38.4\% indicated to have a current student status, $39.3 \%$ were employed. The mean net income was $M=1265.27 €(S D=1228.35)$.

For Study 2b, data was collected in Summer 2017. Participants were addressed through different German online (e.g., Facebook groups) and offline sources (e.g., flyers on the campus). Student participants received course credit for their participation. First, some basic demographic questions were presented, followed by different scales in a randomized order. Items within the scales were also randomized. We collected responses from 294 participants and excluded 52 cases due to missing values on HGO items. In 46 of these excluded cases, participants withdrew early from the study and did not provide any responses for the HGO items. One participant missed two items and five participants missed one item. After this exclusion, the final sample size was $N=242$. The age ranged from 18 to $75(M=$ $30.54, S D=13.70), 75.2 \%$ of the sample was female, $79.3 \%$ not married, $59.1 \%$ in a romantic relationship, $79.8 \%$ indicated to have a general higher education entrance qualification (Abitur), 26.9\% were not employed (including students and unemployed), 42.6\% were employed in full-time or part-time jobs.

\subsubsection{Measures}

In both samples, we assessed HGO using 13 selected items of the scale as described in Study 1. Further, we assessed SWB, extraversion, neuroticism, and basic demographics (e.g., age, gender) in both samples. We assessed additional scales in Study 2a for validation purposes, as well as PWB in Study 2b. For all measures, responses were averaged within scales to create scores. Descriptive statistics and Cronbach's alphas can be found in Table 3 .

Life Satisfaction was measured with the Satisfaction With Life Scale (Diener et al., 1985), which assesses peoples' global judgments of life according to self-chosen criteria. We 
used the German version of Glaesmer, Grande, Braehler, and Roth (2011). Responses were collected with five items on a scale ranging from 1 (disagree completely) to 7 (agree completely). Previous studies demonstrated the convergent, discriminant, and criterion validity of this scale (Diener et al., 1985, 1999; Glaesmer et al., 2011).

Positive and negative affect was assessed in Study 2a with the SPANE (Diener et al., 2009), using the German version of Rahm, Heise, and Schuldt, (2017). Participants were asked to indicate how often they felt a certain affective state during the last two weeks. Responses were collected on a scale ranging from 1 (very rarely or never) to 5 (very often or always). Each facet was measured with three items. Previous studies demonstrated the convergent, criterion, and factorial validity of this scale (Diener et al., 2009; Rahm et al., 2017). In Study 2b, we used the PANAS (Watson et al., 1988) to measure affect by asking participants about the extent they generally feel certain emotions. We used the German translation by Krohne, Egloff, Kohlmann, and Tausch (1996). Responses were collected on a scale ranging from 1 (very slightly or not at all) to 5 (extremely). Both facets were measured with 10 items each. Previous studies demonstrated the convergent, discriminant, criterion, and factorial validity of this scale (Krohne et al., 1996; Watson et al., 1988).

Extraversion and neuroticism were measured in Study 2a with the BFI-10 (Rammstedt, Kemper, Beierlein, and Kovaleva, 2012) with two items each. Evidence for its convergent, discriminant, and factorial validity was provided (Rammstedt, Kemper, Beierlein, and Kovaleva, 2012). In Study 2b, we used the BFI-2-XS (Soto \& John, 2016) and the German version of Danner et al. (2016) to measure extraversion and neuroticism with three items each. Previous studies demonstrated the convergent, discriminant, criterion, and external validity of this scale (Danner et al., 2016; Soto \& John, 2016). For both questionnaires, responses were assessed on a scale ranging from 1 (disagree completely) to 5 (agree completely). 


\section{Measures assessed only in Sample 2a:}

The Valuing Happiness Scale (Mauss et al., 2011) consists of seven items that assess to what extent people value happiness. We used the German version by Luhmann et al. (2016). Responses were collected on a scale from 1 (disagree completely) to 7 (agree completely). Like Luhmann et al. (2016), we considered Item 4 ("I would like to be happier than I generally am") with caution, since it appears to measure experienced unhappiness rather than valuing happiness. The analysis of internal consistency confirmed that this item differs from the others, since dropping it increased the internal consistency from $\alpha=.74$ to $\alpha$ $=.77$. We dropped the item for the investigation of different facets of the scale. Whenever we refer to the complete Valuing Happiness Scale, we used it in the original manner for better comparisons with studies that used the original Valuing Happiness Scale.

Prioritizing Positivity (Catalino et al., 2014) is a scale to measure the explicit pursuit of happiness with six items. The scale was translated into German using the back-translation method (Brislin, 1970). Responses were assessed on a scale ranging from 1 (disagree completely) to 9 (agree completely). Evidence for its criterion and factorial validity was provided (Catalino et al., 2014).

Perceived expectancies to feel happiness were measured with a scale by Bastian et al. (2012). Different adjectives for emotions can be applied within a placeholder in the items, where we inserted the word 'unhappy' (e.g., "When I feel unhappy I feel like a bad person”). Three dimensions were distinguished: self-evaluation (two items), personal expectancies (five items), and social expectancies (six items). The scale was translated into German using the back-translation method (Brislin, 1970). Responses were assessed on a scale ranging from 1 (disagree completely) to 9 (agree completely). Evidence for its criterion and external validity was provided (Bastian et al., 2012). 
BIS and BAS were assessed with a scale by Carver and White (1994), using the German version of Strobel, Beauducel, Debener, and Brocke (2001). We used only 11 of the 24 items and applied Carver and White's (1994) consideration of four dimensions: BAS Drive (two items), BAS Fun Seeking (two items), BAS Reward Responsiveness (two items), and BIS (five items). Responses were collected on a scale ranging from 1 (strong agreement) to 4 (strong disagreement). All items were inverted such that a higher value represents a stronger agreement. Previous studies demonstrated the convergent, discriminant, and criterion validity of this scale (Carver \& White, 1994; McMahan \& Estes, 2011; Nikitin \& Freund, 2010).

Promotion and prevention focus were measured with a scale by Lockwood, Jordan, and Kunda (2002) to assess individual motivations, strategies, and goals. The German version (Dopp, 2013) was adapted by adjusting the context-specific wording to general motivations in life. The prevention subscale includes eight items and the promotion subscale includes nine items. Responses were assessed on a scale ranging from 1 (disagree completely) to 7 (agree completely). Previous studies demonstrated the criterion validity of this scale (Dopp, 2013; Lockwood et al., 2002).

Mood regulation describes the ability to control one's mood states and was measured by the scale by Lischetzke and Eid (2003). Two different effective strategies are distinguished: mood repair (six items) and mood maintenance (five items). Responses were assessed on a scale ranging from 1 (almost never) to 4 (almost always). Evidence for its convergent validity was provided (Lischetzke \& Eid, 2003).

Habitual use of emotion regulation strategies was measured with the questionnaire by Gross and John (2003), using the German version of Abler and Kessler (2009). Two strategies to regulate negative emotional experiences were distinguished: reappraisal (six items) and suppression (four items). Responses were assessed on a scale ranging from 1 
(disagree completely) to 7 (agree completely). Previous studies demonstrated the convergent, discriminant, and criterion validity of this scale (Abler \& Kessler, 2009; Gross \& John, 2003).

To control for data quality, we included one dichotomous item for self-assessment of data quality (see Study 1) and two instructed-response items (e.g., "To assess data quality, please choose response option no. 2"; see Meade \& Craig, 2012).

Measures assessed only in Sample 2b:

PWB was measured with a short version of Ryff 's scale (1989), using the German version of Risch, Strohmayer, and Stangier (2005). The scale distinguishes six facets of positive psychological functioning: autonomy, environmental mastery, personal growth, positive relations with others, purpose in life, and self-acceptance, which are each measured with nine items. Responses were assessed on a scale ranging from 1 (strongly agree) to 6 (strongly disagree). Evidence for its convergent validity was provided (Ryff, 1989).

\subsection{Results}

\subsubsection{Factor Structure and Final Version of the Happiness Goal Orientations Scale}

Confirmatory factor analyses were conducted in the R environment ( $\mathrm{R}$ Development Core Team, 2008) using the package lavaan (Rosseel, 2012) ${ }^{4}$ The factor structure and the final version of HGO were determined by simultaneous considerations of the results of both samples. We used both Maximum Likelihood (ML) and Weighted Least Squares Mean and Variance Adjusted (WLSMV) estimation. ML is characterized by attractive statistical properties and the assumption of continuous indicators ( $\mathrm{Li}, 2016)$, whereas WLSMV was designed for ordered-categorical data and makes fewer assumptions than ML (Lubke \&

\footnotetext{
${ }^{4}$ To reproduce our results, all data files and R-codes can be found online: https://osf.io/dg83m/?view_only=485d5346d5904c90ba3fd21614bd1860
} 
Muthén, 2004; Muthén \& Asparouhov, 2002). WLSMV is particularly recommended if the number of response categories is less than five (Beauducel \& Herzberg, 2006; Dolan, 1994). Both methods have their benefits and limitations. For example, ML performs better regarding differences in approximate fit indices for model comparisons and the estimation of interfactor correlations, whereas WLSMV is more accurate in the estimation of factor loadings (Beauducel \& Herzberg, 2006; Distefano, 2002; Li, 2016; Sass et al., 2014). For these reasons, we considered the results of both estimation methods but prioritized the results of ML for model comparisons (for an overview of CFA results using ML see Table 4; for the results using WLSMV see Table 5).

For the interpretation of model fit, we considered RMSEA and it's 90\% confidence interval, which should be $\leq .05$ for a good fit and $<.08$ for an acceptable fit (Browne $\&$ Cudeck, 1992; Steiger, 1990), SRMR, which should be $<.05$ for a good fit and $<.10$ for an acceptable fit (for ML estimation; Hu \& Bentler, 1995), WRMR, which should be $<1.00$ for a good fit (for WLSMV estimation; DiStefano, Liu, Jiang, \& Shi, 2018), and CFI, which should be $>.97$ for a good fit and $>.95$ for an acceptable fit (Bentler, 1990). Since the twoand the three-factor models were not nested, we used AIC (Akaike, 1998) and BIC (Schwarz, 1978) for model comparisons, where a smaller value indicates a better fit. The results were mostly consistent across the two samples.

In a first step, we tested whether the two-factor solution or the three-factor solution provided a better fit to the data. The parsimonious model contained two latent factors measured by six (anxiety, worries, and focus on threat) and seven (goals, efforts, and activity) indicators. The complex model contained three latent factors measured by four (anxiety \& worries), six (goals, efforts, and activity), and three (focus on threat) indicators. In Sample 2a, AIC did not differ considerably between the models (two-factor model AIC = 17,003.41; three-factor model AIC = 17,002.13), whereas BIC indicated a better fit for the two-factor 
model $(\mathrm{BIC}=17,115.07)$ than for the three-factor model $(\mathrm{BIC}=17,122.06)$. In Sample $2 b$, both criteria indicated a better fit for the three-factor model $(\mathrm{AIC}=8,990.82 ; \mathrm{BIC}=9$ 092.00) than the two-factor model ( $\mathrm{AIC}=9,033.38 ; \mathrm{BIC}=9,127.58)$. The fit statistics were not optimal for both solutions, with slightly better indices for the two-factor model in Sample 2a, and slightly better indices for the three-factor model in Sample 2b when using ML estimation. When using WSLMV estimation, the fit indices were better for the two-factor model in Sample 2a and equivalent in Sample 2b. Altogether, the results regarding the best factor solution were ambivalent.

Statistical models are mathematical approaches and no accurate representations of reality, hence it is necessary to take different criteria into account when choosing the most appropriate model (MacCallum, 2003; Schermelleh-Engel et al., 2003). We decided to prefer the two-factor solution since it is more parsimonious. Additionally, the third factor (focus on threat) of the three-factor model showed several weaknesses in both samples, like high correlations with the first factor, weak loadings of Item 26, and a lower internal consistency than the other factors. The sample size should also be considered for model comparisons. Simple models usually fit better in smaller samples, whereas in larger samples, irrelevant specifications of more complex models tend to become significant (Browne \& Cudeck, 1992; MacCallum, 2003; Schermelleh-Engel et al., 2003). Since the larger Sample 2a suggested that the simple model should be preferred, we can assume with some confidence that this model approaches reality better than the complex model. We labeled the two factors as Happiness-Related Strivings, which represents the propensity to move actively and persistently toward the desired level of happiness, and Happiness-Related Concerns, which represents the propensity to worry about and to focus on threats to one's level of happiness. 
In the next step, we excluded single items on basis of empirical criteria to reach a final version of HGO with five items for each of the two subscales ${ }^{5}$. For this, we considered both fit statistics after exclusion of single items and how the exclusion would affect the reliability of the scales. We decided to remove Items 4, 26, and 27. Item 4 indicated the weakest loadings for the subscale Happiness-Related Concerns in both samples $(2 \mathrm{a} \lambda=.57 ; 2 \mathrm{~b} \lambda=$ $.59)$. Its removal affected the model fit positively $\left(2 \mathrm{a} \mathrm{AIC}_{\mathrm{diff}}=-1317.81, \mathrm{BIC}_{\mathrm{diff}}=-1326.08\right.$; $\left.2 \mathrm{~b} \mathrm{AIC}_{\mathrm{diff}}=-675.02, \mathrm{BIC}_{\mathrm{diff}}=-681.99\right)$ and had only a minor negative $\left(2 \mathrm{a} \alpha_{\text {diff }}=-.01\right)$ or no effect (2b) on the internal consistency. Next, we removed Item 26 from the subscale Happiness-Related Strivings because it had weak loadings in both samples $(2 \mathrm{a} \lambda=.50 ; 2 \mathrm{~b} \lambda=$ $.26)$. Its removal affected the model fit positively $\left(2 \mathrm{a} \mathrm{AIC}_{\mathrm{diff}}=-1287.56, \mathrm{BIC}_{\mathrm{diff}}=-1295.83\right.$; $\left.2 b \mathrm{AIC}_{\text {diff }}=-738.00, \mathrm{BIC}_{\mathrm{diff}}=-744.98\right)$ and had only a minor negative or a positive effect on the internal consistency $\left(2 \mathrm{a} \alpha_{\text {diff }}=-.02 ; 2 \mathrm{~b} \alpha_{\text {diff }}=.02\right)$. Finally, we removed Item 27 from the subscale Happiness-Related Strivings because it had weak loadings in both samples $(2 \mathrm{a} \lambda=$ $.53 ; 2 \mathrm{~b} \lambda=.44)$. Its removal affected the model fit positively $\left(2 \mathrm{a} \mathrm{AIC}_{\mathrm{diff}}=-1323.71, \mathrm{BIC}_{\mathrm{diff}}=\right.$ $\left.-1331.98 ; 2 \mathrm{~b} \mathrm{AIC}_{\mathrm{diff}}=-710.88, \mathrm{BIC}_{\mathrm{diff}}=-717.86\right)$ and had only a minor negative effect on the internal consistency $\left(2 \mathrm{a} \alpha_{\text {diff }}=-.01 ; 2 b \alpha_{\text {diff }}=-.02\right)^{6}$. Overall, these characteristics were similar when using WLSMV estimation.

In a final step, we tested various modifications of the model by allowing indicators to correlate within the two factors. In the best possible solution, we allowed Item 13 and Item 14 to correlate with Item 15 for Happiness-Related Concerns. We also allowed Item 5 and Item 23 to correlate with Item 19, and Item 7 to correlate with Item 9 for Happiness-Related

${ }^{5}$ Figures of the item distributions can be found in the online materials: https://osf.io/dg83m/?view_only=485d5346d5904c90ba3fd21614bd1860

${ }^{6}$ Due to rather weak loadings and the potential to increase model fit we also considered excluding Items 7 or 9. We decided to keep these items, since their exclusion would have had a greater negative impact on the internal consistency (between $\alpha_{\text {diff }}=-.02$ and $\alpha_{\text {diff }}=-.05$ ) than the removal of Item 27. 
Strivings. The fit statistics of the final version were acceptable when using ML estimation (2a $\chi^{2}(29)=97.31 ; \mathrm{CFI}=.95 ; \mathrm{RMSEA}=.07 ; 90 \% \mathrm{CI}[.06 ; .09] ; \mathrm{SRMR}=.07 ; 2 \mathrm{~b} \chi^{2}(29)=63.53 ;$ $\mathrm{CFI}=.96 ; \mathrm{RMSEA}=.07 ; 90 \% \mathrm{CI}[.05 ; .09] ;$ SRMR $=.07)$ and slightly worse when using WLSMV estimation $\left(2 \mathrm{a} \chi^{2}(29)=177.28 ; \mathrm{CFI}=.96 ; \mathrm{RMSEA}=.11 ; 90 \% \mathrm{CI}[.09 ; .12]\right.$; $\mathrm{WRMR}=1.30 ; 2 \mathrm{~b} \chi^{2}(29)=103.19 ; \mathrm{CFI}=.97 ; \mathrm{RMSEA}=.10 ; 90 \% \mathrm{CI}[.08 ; .13] ; \mathrm{WRMR}=$ $1.05)$.

The final items are shown in the Appendix. Psychometric properties of the final version of the measure were $M=2.82, S D=0.97, \alpha=.84$ (Study 2a) and $M=2.56, S D=$ $1.04, \alpha=.87$ (Study 2b) for Happiness-Related Concerns and $M=3.03, S D=0.73, \alpha=.73$ (Study 2a) and $M=3.07, S D=0.72, \alpha=.70$ (Study 2b) for Happiness-Related Strivings. The correlation between the scales was $r=.20$ (2a) and $r=.09$ (2b). Happiness-Related Concerns correlated significantly with age ( $2 \mathrm{a} r=-.20 ; 2 \mathrm{~b} r=-.33)$, but Happiness-Related Strivings did not (2a $r=-.08 ; 2 \mathrm{~b} r=-.09)$. In Study 2a, male participants reported significantly lower Happiness-Related Concerns than female participants $\left(F(1,457)=5.89, p=.016, M_{\text {diff }}=\right.$ 0.25). No significant gender differences could be found for Happiness-Related Strivings $\left(F(1,457)=3.84, p=.051, M_{\text {diff }}=-0.15\right)$. In Study $2 b$, no significant gender differences could be found for both Happiness-Related Concerns $\left(F(1,238)=1.13, p=.289, M_{\text {diff }}=-0.17\right)$ and Happiness-Related Strivings $\left(F(1,238)=0.25, p=.617, M_{\text {diff }}=-0.06\right)$.

\subsubsection{Validity of the Happiness Goal Orientations Scale}

To investigate the construct validity of $\mathrm{HGO}$, we examined correlations between the HGO subscales and related constructs. Generally, the correlation patterns were as expected and consistent with our expectations: Approach-related constructs and a focus on positivity correlated positively with Happiness-Related Strivings (e.g., prioritizing positivity $r=.41$, promotion focus $r=.37$, emotion regulation reappraisal $r=.25$ ), whereas avoidance-related constructs and a focus on anxiety correlated positively with Happiness-Related Concerns 
(e.g., prevention focus $r=.72$, neuroticism $r=.54$, BIS $r=.24$ ). Happiness-Related Concerns were associated with poor abilities to regulate one's moods and emotions (e.g., mood repair $r$ $=-.58)$ and perceived social expectancies regarding the own level of happiness $(r=.36)$. Happiness-Related Strivings correlated not as strongly and consistently with abilities to regulate one's moods and emotions (e.g., mood maintenance $r=.12$ ) and with personal expectancies regarding the own level of happiness $(r=.28)$ but not with perceived social expectancies regarding the own level of happiness $(r=.05$; see Table 6$)$.

Following the suggestions by Luhmann et al. (2016), we considered associations with a multidimensional version of the Valuing Happiness Scale. For this, we compared three possible model solutions of the Valuing Happiness Scale, which revealed that a two-factor model is most appropriate. Factor 1 represented an emphasis on the importance of happiness in life, whereas Factor 2 represented happiness-related anxieties and worries. Only the second factor correlated significantly with Happiness-Related Concerns, $r=.31$, whereas both factors correlated significantly with Happiness-Related Strivings, $r=.33$ and $r=.30$.

To identify the variables with the highest predictive power after controlling for shared variance with other variables, we conducted two regression analyses with the HGO dimensions as criterion variables and all investigated variables as predictors. The variance inflation factor (calculated with the package car, Fox \& Weisberg, 2011) indicated no problems with multicollinearity. Variables in the regression analyses differed in measurement scale length and were all standardized for better interpretability and comparability (Hunter \& Hamilton, 2002). Significant predictors for Happiness-Related Strivings were prioritizing positivity, personal expectancies to feel happiness, BAS drive, promotion focus, and emotion regulation reappraisal. Significant predictors of Happiness-Related Concerns were prevention focus, mood repair (negative), and neuroticism (Table 7). These results provide evidence for the construct validity of $\mathrm{HGO}$, since the significant predictors of Happiness-Related Strivings 
were approach-related constructs and a focus on positivity, whereas the significant predictors of Happiness-Related Concerns were avoidance-related constructs, anxiety, and poor mood regulation abilities.

\subsubsection{Happiness Goal Orientations and Subjective Well-Being}

To resolve disagreements in the literature regarding the relations of HGO-related constructs and well-being, we computed hierarchical multiple regressions for each of the three SWB facets being predicted by the two HGO subscales in both samples, controlling for age and gender (Study 2a: Table 8; Study 2b: Table 10). The variance inflation factor indicated no problems with multicollinearity for all analyses described below. Variables in the regression analyses differed in measurement scale length and were all standardized (except age and gender) for better interpretability and better comparability between the effect sizes of different regression models and studies throughout this article (Hunter \& Hamilton, 2002). The directions of the effects corresponded with the bivariate correlations (Study 2a: Table 6; Study 2b: Table 9). Happiness-Related Concerns were a negative predictor for life satisfaction and positive affect, and a positive predictor for negative affect across both samples. The effects for Happiness-Related Strivings were in the opposite direction, generally smaller, and in most cases not significant for negative affect. These results confirmed our predictions.

To provide evidence for the incremental validity of the HGO Scale, we added the two factors of the Valuing Happiness Scale in the model (Sample 2a only). The direction of the effects corresponded with the HGO Scale: Valuing Happiness Factor 1 was a positive predictor of life satisfaction and positive affect, whereas Factor 2 was a negative predictor of positive affect. Both Valuing Happiness factors were no significant predictors of negative affect. Controlling for Valuing Happiness only slightly decreased the predictive utility of 
HGO. Overall, the predictive utility was greater for the HGO in comparison to the Valuing Happiness factors.

Next, we added extraversion and neuroticism as control variables, which decreased the predictive utility of HGO: In Sample 2a, the regression coefficients of the HGO dimensions decreased but remained significant for all SWB facets, except for the association between Happiness-Related Strivings and negative affect. For the Valuing Happiness Scale, adding extraversion and neuroticism hardly affected Factor 1, whereas Factor 2 was no longer significant for no well-being outcome. In Sample 2b, Happiness-Related Strivings remained a significant predictor of positive affect and Happiness-Related Concerns remained a significant predictor of life satisfaction, whereas the HGO dimensions were no longer significantly associated with facets of SWB.

\subsubsection{Happiness Goal Orientations and Psychological Well-Being}

Hierarchical multiple regressions for each of the six PWB facets as criteria and the two HGO subscales as predictors, controlling for age and gender, revealed that HappinessRelated Strivings were a positive predictor, whereas Happiness-Related Concerns were a negative predictor of PWB (Table 11). In contrast to the bivariate correlations of HappinessRelated Strivings (Table 9), both predictors were significantly associated with all PWB facets. These results confirmed our predictions.

Finally, we added extraversion and neuroticism as control variables, which decreased the associations between HGO and PWB: Happiness-Related Strivings remained a significant predictor for three facets. For Happiness-Related Concerns, the predictive power of the HGO dimensions remained significant but decreased considerably for most of the PWB facets. Only for personal growth, the regression coefficient was similar to the model without extraversion and neuroticism. The variance inflation factor indicated no problems with 
multicollinearity for all analyses described in this section. As for the multiple regressions predicting SWB, all variables except age and gender were standardized.

\subsection{Discussion}

The main purpose of Studies $2 \mathrm{a}$ and $2 \mathrm{~b}$ was to identify the factorial structure of the HGO Scale and to determine the final version of the scale. Overall, the results favored the two-factor model and demonstrated its good psychometric properties. Further, we provided evidence for the construct validity of HGO: Happiness-Related Strivings were particularly associated with approach-related constructs and a focus on positivity, whereas HappinessRelated Concerns were particularly associated with avoidance-related constructs, anxiety, and poor mood regulation abilities. These studies also showed that the HGO dimensions were differentially related to well-being: Happiness-Related Strivings were positively associated with SWB and PWB, whereas Happiness-Related Concerns were negatively associated with SWB and PWB. This result highlights the importance of considering $\mathrm{HGO}$ as a multidimensional construct.

\section{Study 3}

The goal of Study 3 was to replicate the results of Studies $2 \mathrm{a}$ and $2 \mathrm{~b}$ regarding the model fit of the HGO scale and its associations with well-being. To provide further evidence of the construct validity of the HGO scale, we also investigated relations between the HGO dimensions with happiness definitions, orientations to a happy life, and intentions to pursue specific happiness definitions in everyday life.

In the past, happiness has been defined in many different ways (for overviews see Intelisano et al., 2019; Kesebir \& Diener, 2008; Tov, 2018) and people differ regarding the specific definitions they endorse and consider as important and necessary ingredients of happiness (Krasko et al., 2020; McMahan \& Estes, 2011; Peterson et al., 2005). Most 
prominently, happiness has been defined as the experience of joy or pleasure, the absence of negative emotions or experiences, continuous development of oneself, and as belonging or contribution to a social circle (Krasko et al., 2020; McMahan \& Estes, 2011). Other happiness definitions include tranquility, a sense of purpose, and luck (Krasko et al., 2020). How people define happiness for themselves differs from the specific aspects of happiness people actually pursue in everyday life (Krasko et al., 2020). For this reason, it is important to assess happiness definitions separately from intentions to pursue specific happiness definitions. In this study, we investigated the relations between HGO and both individual differences in happiness definitions and intentions to pursue specific happiness definitions in everyday life.

We preregistered ${ }^{7}$ the expectation that Happiness-Related Strivings would be positively associated with defining happiness as positive attitude and personal development, as well as with the intention to pursue these happiness definitions in everyday life. Further, we expected that Happiness-Related Concerns would be positively associated with defining happiness as the absence of negativity and negatively associated with defining happiness as personal development. We expected the same associations regarding intentions to pursue these happiness definitions in everyday life.

The reported variables and results are part of a preregistered study with a different main focus and different goals (Krasko et al., 2020). Therefore, we report only the methods, variables, and results relevant for $\mathrm{HGO}$ in this article.

${ }^{7}$ As soon as the corresponding article is publicly available, the preregistration will also be publicly available following this link: https://osf.io/apj9m/. Please note that we refer to outdated labels for the scales in the preregistration (Significance of Happiness instead of Happiness Goal Orientations; Active Pursuit of Happiness instead of Happiness-Related Strivings; Unhappiness as Threat instead of Happiness-Related Concerns; openness for development instead of personal development). 


\subsection{Methods}

\subsubsection{Participants and Procedure}

For data collection, we used the online survey software Qualtrics. Data was collected in November 2017. Participants were recruited through different German online and offline sources (e.g., mailing lists, Facebook groups, flyers on the campus). Student participants received course credit for their participation. All participants could participate in a lottery of Amazon vouchers worth $600 €$ in total. Informed consent was obtained from all participants included in the study. First, different scales were presented in a randomized order. Items within the scales were also randomized. At the end of the survey, we presented some basic demographic questions. We collected responses from 334 participants and excluded four cases on basis of an item for the self-assessment of data quality and 22 cases due to missing values or failed responses to two instructed response items. After these exclusions, the final sample size was $N=279$, which is appropriate for stable estimates of correlations (Schönbrodt \& Perugini, 2013) and the conduction of confirmatory factor analyses (Barrett, 2007; Wolf et al., 2013). The age ranged from 18 to $80(M=25.88, S D=7.75), 84.6 \%$ of the sample was female, $88.2 \%$ not married, $64.2 \%$ in a romantic relationship, $73.9 \%$ indicated to have a general higher education entrance qualification (Abitur), 55.6\% indicated to have a current student status, $25.1 \%$ were employed.

\subsubsection{Measures}

We assessed the final version of HGO, life satisfaction, extraversion, and neuroticism with the BFI-2-XS, basic demographics, and items to control for data quality as described in Studies $2 \mathrm{a}$ and $2 \mathrm{~b}$. We assessed positive and negative affect with the SPANE as in Study $2 \mathrm{a}$. In this Study, however, each facet was measured with six items, and participants were asked to indicate how often they felt a certain affective state during the last four weeks. We 
assessed PWB as in Study 2b. In this Study, however, each facet was measured with three items. Unless stated otherwise below, responses were collected using a scale ranging from 1 (disagree strongly) to 5 (agree strongly) and were averaged within scales to create scores. Descriptive statistics and Cronbach's alphas can be found in Table 12.

Happiness definitions and intentions to pursue happiness were assessed with the DIDI (Krasko et al., 2020). This tool provides two parallel scales to measure different lay definitions of happiness as well as intentions to pursue these happiness definitions in everyday life, respectively. Both scales consist of eight factors (positive attitude, tranquility, joy and desires, absence of negativity, personal development, purpose, belonging, and luck), each measured with three items. The items were phrased as a completion of a specific item stem, which is "For me personally, happiness means..." (e.g., "...to be connected to others of the own community") for happiness definitions and "In daily life, I try..." (e.g., "...to be connected to others of my community") for intentions to pursue happiness. Responses were collected using asymmetric scale labels with one level for true rejection $(1=$ does not apply $)$ and five levels indicating different nuances of agreement (from $2=$ applies hardly to $6=$ applies completely). Evidence for the convergent, discriminant, factorial, and criterion validity of the scales was provided (Krasko et al., 2020).

The 16-item Beliefs About Well-Being Scale of McMahan and Estes (2011) was used to assess the extent to which people agree with four different lay definitions of happiness: The experience of pleasure, the avoidance of negative experiences, self-development, and contribution to others. The scale was translated into German using the back-translation method (Brislin, 1970). Previous studies demonstrated the convergent, discriminant, criterion, and factorial validity of this scale (Krasko et al., 2020; McMahan \& Estes, 2011).

The Orientations to Happiness Scale of Peterson et al. (2005) assesses people's orientations to pleasure, engagement, and meaning in life with six items each. The German 
version was provided by Ruch, Harzer, Proyer, Park, and Peterson (2010). Previous studies demonstrated the convergent, criterion, and factorial validity of this scale (McMahan \& Estes, 2011; Peterson et al., 2005; Ruch et al., 2010).

\subsection{Results}

\subsubsection{Model Fit and Psychometric Properties of the Happiness Goal Orientations}

Scale

To investigate the model fit of the final HGO scale, we applied the same approaches and criteria as described in Studies $2 \mathrm{a}$ and $2 \mathrm{~b}^{8}$. First, we tested the two-factor model with five indicators each using CFA and both ML and WLSMV estimation. Results revealed unsatisfying to acceptable fit statistics for both estimation methods, with $\chi^{2}(34)=146.04$; CFI $=.91 ; \mathrm{RMSEA}=.11 ; 90 \% \mathrm{CI}[.09 ; .13]$;RMR $=.07$ for $\mathrm{ML}$ and $\chi^{2}(34)=183.272 ; \mathrm{CFI}=$ .96 ; RMSEA $=.13 ; 90 \%$ CI $[.11 ; .14]$; WRMR $=1.35$ for WLSMV. Allowing indicators to correlate within the two factors as described in Studies $2 \mathrm{a}$ and $2 \mathrm{~b}$ significantly improved the model fit (ML estimation: $\chi^{2}(5)=83.14, p<.001$; WLSMV estimation using the correction by Satorra, 2000: $\left.\chi^{2}(5)=98.88, p<.001\right)$. The final model fit was overall good for both ML estimation $\left(\chi^{2}(29)=62.89 ; \mathrm{CFI}=.97 ; \mathrm{RMSEA}=.07 ; 90 \% \mathrm{CI}[.04 ; .09]\right.$; SRMR $\left.=.06\right)$ and WLSMV estimation $\left(\chi^{2}(29)=105.84 ;\right.$ CFI $=.98 ;$ RMSEA $=.10 ; 90 \%$ CI $[.08 ; .12]$; WRMR $=1.00)$.

Psychometric properties of the measure were $M=3.08, S D=1.10, \alpha=.89$ for Happiness-Related Concerns and $M=3.07, S D=0.76, \alpha=.78$ for Happiness-Related Strivings ${ }^{9}$. The correlation between the scales was $r=.18$. Happiness-Related Concerns

\footnotetext{
${ }^{8}$ To reproduce our results, all data files and R-codes can be found online: https://osf.io/dg83m/?view_only=485d5346d5904c90ba3fd21614bd1860

${ }^{9}$ Figures of the item distributions can be found in the online materials: https://osf.io/dg83m/?view_only=485d5346d5904c90ba3fd21614bd1860
} 
correlated significantly with age $(r=-24)$ but Happiness-Related Strivings did not $(r=-.11)$. Male participants reported significantly lower Happiness-Related Concerns than female participants $\left(F(1,275)=8.86, p=.003, M_{\text {diff }}=-0.55\right)$. No gender differences could be found for Happiness-Related Strivings $\left(F(1,275)=1.73, p=.190, M_{\text {diff }}=0.17\right)$.

\subsubsection{Happiness Goal Orientations, Happiness Definitions, and Happiness-related}

\section{Intentions}

To provide further evidence of construct validity, we examined correlations between the HGO dimensions and happiness definitions as well as intentions to pursue happiness (Table 13). Against our expectations, Happiness-Related Strivings correlated not only positively with defining happiness as positive attitude $(r=.14)$ and personal development $(r$ $=.21$ ), but also with various other happiness definitions and orientations to a happy life (e.g., orientation to pleasure $r=.30$, orientation to engagement $r=.22$, defining happiness as having purpose in life $r=.20$ ). In line with our expectations, Happiness-Related Concerns correlated positively with defining happiness as the absence of negativity $(r=.26)$ and negatively, but not significantly, with defining happiness as personal development $(r=-.11)$. In contrast to our expectations, the correlation patterns were different for intentions to pursue happiness: Happiness-Related Strivings correlated positively with intentions to pursue most happiness definitions in everyday life (e.g., purpose $r=.40$, positive attitude $r=.20$, personal development $r=.24$, absence of negativity $r=.23$ ). Happiness-Related Concerns correlated negatively with many intentions to pursue happiness definitions in everyday life (e.g., positive attitude $r=-.45$, tranquility $r=-.27$, personal development $r=-.26$ ) and it correlated not at all with the intention to pursue the absence of negativity in everyday life $(r=.03)$.

\subsubsection{Happiness Goal Orientations and Subjective Well-Being}

To replicate the results of Studies $2 \mathrm{a}$ and $2 \mathrm{~b}$ regarding the associations with wellbeing, we conducted the same analyses as described in these studies. The variance inflation 
factor indicated no problems with multicollinearity for all analyses described in this section. As for the multiple regressions in Studies $2 \mathrm{a}$ and $2 \mathrm{~b}$, all variables except age and gender were standardized. For SWB, the directions of the effects of the hierarchical multiple regression analyses (Table 14) corresponded with the bivariate correlations (Table 13). HappinessRelated Concerns were a negative predictor for life satisfaction and positive affect, and a positive predictor for negative affect. The effects for Happiness-Related Strivings were in the opposite direction to those for Happiness-Related Concerns, generally smaller, and significant for the multiple regression analysis but not significant for the correlations. Adding extraversion and neuroticism as control variables decreased the predictive utility of $\mathrm{HGO}$, although all predictors remained significant except Happiness-Related Strivings predicting negative affect. These results are in line with the results of Studies $2 \mathrm{a}$ and $2 \mathrm{~b}$ and confirmed our expectations.

\subsubsection{Happiness Goal Orientations and Psychological Well-Being}

Hierarchical multiple regressions for the PWB facets as criteria confirmed the result that Happiness-Related Strivings were a positive predictor, whereas Happiness-Related Concerns were a negative predictor of PWB (Table 15). Like in Study 2b, the predictors were significantly associated with most of the PWB facets, although the bivariate correlations of Happiness-Related Strivings were not significant. These results confirmed our predictions. Adding extraversion and neuroticism as control variables decreased the associations between HGO and PWB: Happiness-Related Strivings remained a significant predictor for three facets. For Happiness-Related Concerns, the predictive power of the HGO dimensions remained significant for four PWB facets but decreased considerably for most PWB facets. The variance inflation factor indicated no problems with multicollinearity for all analyses described in this section. As for the multiple regressions predicting SWB, all variables except age and gender were standardized. 


\subsection{Discussion}

With this study, we confirmed the results of Studies $2 \mathrm{a}$ and $2 \mathrm{~b}$ regarding the model fit of the HGO scale. Further, we investigated relations between the HGO dimensions with happiness definitions, orientations to a happy life, and intentions to pursue happiness definitions. Although our preregistered expectations for these correlation patterns were not completely met, these results provide evidence for the construct validity of HGO: HappinessRelated Strivings were associated with endorsing a broad range of happiness definitions and also with the intention to pursue these different happiness definitions, including positive things but also the absence of negativity. This highlights that the important feature of Happiness-Related Strivings is whether happiness is approached actively and fearlessly, even if aiming at the prevention of unhappiness in life. Happiness-Related Concerns, however, were associated with defining happiness solely as the absence of negativity and having no intentions to pursue happiness, not even the absence of negativity. Further, we confirmed the results of Studies $2 \mathrm{a}$ and $2 \mathrm{~b}$ by showing that Happiness-Related Strivings were positively associated with SWB and PWB, whereas Happiness-Related Concerns were negatively associated with SWB and PWB, which again highlights the importance of considering HGO as a multidimensional construct.

\section{General Discussion}

In this article, we presented four studies in which we developed and validated a multidimensional measure of $\mathrm{HGO}$ and applied this scale to reevaluate and integrate existing findings on the relations between HGO and well-being. We found a two-dimensional structure of HGO and showed that depending on the dimension, HGO can be both advantageous and detrimental for one's well-being. 


\subsection{The Multidimensional Structure of Happiness Goal Orientations}

Driven by theories that distinguish different dimensions of motivational systems and goal pursuit, we developed the Happiness Goal Orientations Scale, a novel measure of individual differences in approaches to attain or maintain a sufficient level of happiness in life. The final version of the scale had good psychometric properties and consisted of five items for each of the two dimensions Happiness-Related Strivings and Happiness-Related Concerns.

Happiness-Related Strivings represent the propensity to move actively toward the desired level of happiness. This is in line with theories and measures that consider an active and persistent pursuit of goals as an independent dimension, like the most commonly used BAS scales (Carver \& White, 1994; Corr \& Cooper, 2016; Hartig \& Moosbrugger, 2003), action orientation (Kuhl, 1984, 2000), or promotion focus (Higgins, 1997; Lockwood et al., 2002). The important feature of Happiness-Related Strivings is whether happiness is approached actively and fearlessly, even if aiming at the prevention of unhappiness in life. This is also emphasized by the result that this dimension is associated with the intention to pursue different happiness definitions in everyday life, including positive things but also the absence of negativity. Happiness-Related Strivings were associated with approach-related constructs, positivity, successful strategies to regulate one's moods and emotions, and endorsing a broad range of happiness definitions.

Happiness-Related Concerns represent the propensity to worry about and to focus on threats to one's level of happiness. This is in line with theories and measures that consider anxiety, worries, and a tendency to ruminate regarding the desired goals, like most commonly used BIS scales (Carver \& White, 1994; Corr \& Cooper, 2016; Hartig \& Moosbrugger, 2003), state orientation (Kuhl, 1984, 2000), or prevention focus (Higgins, 1997; Lockwood et al., 2002). Happiness-Related Concerns were associated with avoidance-related scales, 
anxiety, poor strategies to regulate one's moods and emotions, perceived social expectancies to feel happy, defining happiness solely as the absence of negativity, and having no intentions to pursue happiness in everyday life.

In the theories and measures listed above, the initiation and maintenance of goals, which might include adequate anticipation and handling of setbacks, is contrasted with a tendency to ruminate regarding possible goals, which might result in an overcautious suppression of change processes. In sum, individual differences in the pursuit of goals can be applied to HGO. The important feature of the multidimensional consideration of HGO is whether happiness is approached actively and fearlessly, in contrast to whether people tend to reflect and ruminate regarding the own level of happiness and to be anxious not to reach the desired level of happiness. Similarly, Joshanloo (2019) identified "effortful virtuosity vs. doubtful pursuit" as one of two underlying dimensions to describe differences between lay conceptions of happiness. One side of the dimension is characterized as the active pursuit of happiness, whereas the opposite side of the dimension is characterized as doubt about the achievability of happiness.

\subsection{Happiness Goal Orientations and Well-Being}

As expected, Happiness-Related Strivings were positively and Happiness-Related Concerns were negatively associated with both SWB and PWB. The associations between well-being and Happiness-Related Concerns were generally stronger and more consistent than the associations between well-being and Happiness-Related Strivings, indicating that to worry and to focus on threats to one's level of happiness appears to play a more critical role for well-being than the intention to actively pursue happiness-related goals. Further, the results indicated that HGO is associated with SWB and PWB in a similar fashion, which is consistent with the results by Mauss et al. (2011). 
These findings reconcile conflicting results in the literature, where some found a positive relation between HGO-related constructs and well-being (Catalino et al., 2014; Peterson et al., 2005), whereas others found the opposite (Martin, 2008; Mauss et al., 2011; McGuirk et al., 2018). Varying associations of well-being with both HGO and the Valuing Happiness factors highlight the importance of a multidimensional consideration of HGO and related constructs: The Valuing Happiness Scale as introduced in the first publication where it was used (Mauss et al., 2011) correlated negatively with well-being, which can only be observed for one factor when considering the scale in a multidimensional manner. Thus, without this multidimensional consideration, we would have come to the same conclusion as previous investigations which showed that the HGO-related construct Valuing Happiness is detrimental for well-being (e.g., Mauss et al., 2012, 2011). This is in line with varying associations of different dimensions considered in theories of motivational systems and goal pursuit with well-being (Briki, 2018; Churchyard \& Buchanan, 2017; Elliot \& Thrash, 2002; Updegraff et al., 2004). We can conclude that whether HGO is advantageous or detrimental for well-being differs between the HGO dimensions.

Controlling for age and gender revealed both shared variances with $\mathrm{HGO}$ as well as suppression effects by uncovering significant effects of age and gender only after the HGO dimensions were added. However, the patterns of these observations were quite inconsistent between the different studies and outcomes and were often only observed at the lower thresholds of significance. HGO had predictive utility beyond the Valuing Happiness Scale, indicating that goal orientations are a more proximal predictor of actual well-being than general values. Also, many associations between $\mathrm{HGO}$ and well-being were robust after controlling for extraversion and neuroticism, although this result was somewhat inconsistent between the different Studies. 


\subsection{Implications for the Pursuit of Happiness}

In this article, we showed that depending on the dimension HGO can be both advantageous and detrimental for one's well-being. Pursuing happiness-related goals with effort and persistence is associated with higher success in this striving. Therefore, we assume that the "dark side of happiness" as a consequence of an extreme valuing or pursuit of happiness (Gruber et al., 2011, p. 222) can be explained by a focus on concerns regarding one's level of happiness. This focus might arise from low expectancies to regulate one's mood (Fergus \& Bardeen, 2016) or a perceived social pressure not to be unhappy (McGuirk et al., 2018), and result in a continuous monitoring of one's progress toward happiness goals that in turn interferes with the experience of happiness (Ford and Mauss, 2014).

Further, the positive relation between Happiness-Related Strivings and well-being is considerably weaker and less consistent across studies than the negative relation between Happiness-Related Concerns and well-being. Therefore, it appears particularly crucial for the pursuit of happiness goals not to worry about but to accept undesired outcomes like negative affective experiences as an important part of life. This is in accordance with the work by Ford et al. (2018) who found that the acceptance of negative emotions predicted lower negative emotional responses. In certain circumstances, negative affect fulfills an important function and should not generally be avoided (Gruber et al., 2011). Facilitating the acceptance of negative emotions is an established approach in therapeutic work (Hayes, 2016; Hofmann \& Asmundson, 2008), affects well-being positively (Ford et al., 2018; Luong et al., 2016), and facilitates less negative relations between positive and negative emotional experiences (Grossmann et al., 2014; Schimmack, Oishi, et al., 2002). Contemporary western cultures tend to pursue the avoidance of negativity (Joshanloo, 2014; Pflug, 2009; Uchida \& Ogihara, 2012). Instead, a greater appreciation and acceptance of negative emotionality as an important part of life might be worth striving for. 


\subsection{Limitations and Future Research}

One limitation of the present findings is the lack of cultural diversity of our samples since relations between HGO-related constructs and well-being differ among cultures (Ford, Dmitrieva, et al., 2015). These varying relations might result from cultural differences in norms for emotional experiences and definitions of happiness (Bastian et al., 2014; Curhan et al., 2014; Eid \& Diener, 2001; Oishi et al., 2013). Consequently, we cannot expect the results to replicate in populations with different cultural backgrounds. Therefore, an important next step would be to develop and validate translated versions of the HGO Scale and to investigate whether the present findings differ among cultures.

Another limitation is the correlational and cross-sectional nature of the present findings that do not allow any conclusions about the causal direction of the associations between $\mathrm{HGO}$ and well-being. We assume that well-being is not only a result of differences in emotion, cognition, and motivation associated with different orientations toward happiness goals but also that actual levels of well-being determine available resources to approach and reach happiness-related goals (see Catalino et al., 2014; Fredrickson, 2013; Haase et al., 2012). Therefore, potential reinforcing mechanisms between HGO and well-being should be investigated longitudinally and experimentally in the future. For example, experience sampling methodology would allow investigating whether the HGO dimensions are related to well-being on the following day and vice versa. However, to completely resolve questions of causality, experimental manipulations of the HGO dimensions should be used to investigate their differential associations with well-being.

\section{Conclusion}

In this article, we developed and validated the HGO Scale, which distinguishes the two dimensions Happiness-Related Strivings and Happiness-Related Concerns. Happiness- 
Related Strivings represent the propensity to move actively and persistently toward the desired level of happiness and are positively associated with well-being. Happiness-Related Concerns represent the propensity to worry about and to focus on threats to one's level of happiness and are negatively associated with well-being. These differential associations with well-being demonstrate the importance of considering HGO as a multidimensional construct and that HGO can be both beneficial and detrimental to one's level of well-being. 


\section{References}

Abler, B., \& Kessler, H. (2009). Emotion Regulation Questionnaire - Eine deutschsprachige Fassung des ERQ von Gross und John. Diagnostica, 55(3), 144-152. https://doi.org/10.1026/0012-1924.55.3.144

Agbo, A. A., \& Ngwu, C. N. (2017). Aversion to happiness and the experience of happiness: The moderating roles of personality. Personality and Individual Differences, 111, 227231. https://doi.org/10.1016/j.paid.2017.02.010

Akaike, H. (1998). Information theory and an extension of the maximum likelihood principle. In Selected papers of hirotugu akaike (pp. 199-213). Springer.

Back, M. D., Küfner, A. C. P., Dufner, M., Gerlach, T. M., Rauthmann, J. F., \& Denissen, J. J. A. (2013). Narcissistic admiration and rivalry: Disentangling the bright and dark sides of narcissism. Journal of Personality and Social Psychology, 105(6), 1013-1037. https://doi.org/10.1037/a0034431

Barrett, P. (2007). Structural equation modelling: Adjudging model fit. Personality and Individual Differences, 42(5), 815-824. https://doi.org/10.1016/j.paid.2006.09.018

Bastian, B., Kuppens, P., De Roover, K., \& Diener, E. F. (2014). Is valuing positive emotion associated with life satisfaction? Emotion, 14(4), 639-645.

https://doi.org/10.1037/a0036466

Bastian, B., Kuppens, P., Hornsey, M. J., Park, J., Koval, P., \& Uchida, Y. (2012). Feeling bad about being sad: The role of social expectancies in amplifying negative mood. Emotion, 12(1), 69-80. https://doi.org/10.1037/a0024755

Beauducel, A., \& Herzberg, P. Y. (2006). On the performance of maximum likelihood versus means and variance adjusted weighted least squares estimation in CFA. Structural Equation Modeling, 13(2), 186-203. https://doi.org/10.1207/s15328007sem1302_2

Bentler, P. M. (1990). Comparative Fit Indexes in Structural Models. Psychological Bulletin, 107(2), 238-246. https://doi.org/10.1037/0033-2909.107.2.238

Bolier, L., Haverman, M., Westerhof, G. J., Riper, H., Smit, F., \& Bohlmeijer, E. (2013). Positive psychology interventions: a meta-analysis of randomized controlled studies. BMC Public Health, 13(119). https://doi.org/10.1186/1471-2458-13-119

Briki, W. (2018). Trait self-control: Why people with a higher approach (avoidance) temperament can experience higher (lower) subjective wellbeing. Personality and Individual Differences, 120, 112-117. https://doi.org/10.1016/j.paid.2017.08.039

Brislin, R. W. (1970). Back-translation for cross-cultural research. Journal of Cross-Cultural Psychology, 1(3), 185-216. https://doi.org/10.1177/135910457000100301

Browne, M. W., \& Cudeck, R. (1992). Alternative ways of assessing model fit. Sociological Methods \& Research, 21(2), 230-258. https://doi.org/10.1177/0049124192021002005

Carver, C. S., \& White, T. L. (1994). Behavioral inhibition, behavioral activation, and affective responses to impending reward and punishment: The BIS/BAS scales. Journal of Personality and Social Psychology, 67(2), 319-333. https://doi.org/http://dx.doi.org/10.1037/0022-3514.67.2.319

Catalino, L. I., Algoe, S. B., \& Fredrickson, B. L. (2014). Prioritizing positivity: An effective approach to pursuing happiness? Emotion, 14(6), 1155-1161. 
https://doi.org/10.1037/a0038029

Churchyard, J. S., \& Buchanan, K. (2017). Which way to well-being: "More of the same" or "trying something novel"? The association of comfortable and experimental behavior styles to well-being. Personality and Individual Differences, 109, 35-43. https://doi.org/10.1016/j.paid.2016.12.037

Corr, P. J., \& Cooper, A. J. (2016). The Reinforcement Sensitivity Theory of Personality Questionnaire (RST-PQ): Development and validation. Psychological Assessment, 28(11). https://doi.org/http://dx.doi.org/10.1037/pas0000273

Curhan, K. B., Sims, T., Markus, H. R., Kitayama, S., Karasawa, M., Kawakami, N., Love, G. D., Coe, C. L., Miyamoto, Y., \& Ryff, C. D. (2014). Just how bad negative affect is for your health depends on culture. Psychological Science, 25(12), 2277-2280. https://doi.org/10.1177/0956797614543802

Danner, D., Rammstedt, B., Bluemke, M., Treiber, L., Berres, S., Soto, C. J., \& John, O. (2016). Die deutsche Version des Big Five Inventory 2 (BFI-2). Zusammenstellung Sozialwissenschaftlicher Items Und Skalen. https://doi.org/10.6102/zis247

Datu, J. A. D., \& King, R. B. (2016). Prioritizing positivity optimizes positive emotions and life satisfaction: A three-wave longitudinal study. Personality and Individual Differences, 96, 111-114. https://doi.org/10.1016/j.paid.2016.02.069

Diener, E. F. (1984). Subjective well-being. Psychological Bulletin, 95(3), 542-575. https://doi.org/10.1037/0033-2909.95.3.542

Diener, E. F., Emmons, R. A., Larsen, R. J., \& Griffin, S. (1985). The Satisfaction With Life Scale. Journal of Personality Assessment, 49(1), 71-75. https://doi.org/10.1207/s15327752jpa4901_13

Diener, E. F., Lucas, R. E., \& Suh, E. M. (1999). Cross-cultural variations in predictors of life satisfaction: Perspectives from needs and values. Personality and Social Psychology Bulletin, 25(8), 980-990.

Diener, E. F., Sapyta, J. J., \& Suh, E. (1998). Subjective well-being is essential to well-being. Psychological Inquiry, 9(1), 33-37. https://doi.org/https://doi.org/10.1207/s15327965pli0901_3

Diener, E. F., Wirtz, D., Tov, W., Kim-Prieto, C., Choi, D. W., Oishi, S., \& Biswas-Diener, R. (2009). New well-being measures: Short scales to assess flourishing and positive and negative feelings. Social Indicators Research, 97(2), 143-156. https://doi.org/10.1007/s11205-009-9493-y

Disabato, D. J., Goodman, F. R., Kashdan, T. B., Short, J. L., \& Jarden, A. (2016). Different types of well-being? A cross-cultural examination of hedonic and eudaimonic wellbeing. Psychological Assessment, 28(5), 471-482. https://doi.org/10.1037/pas0000209

Distefano, C. (2002). The Impact of Categorization With Confirmatory Factor Analysis. Structural Equation Modeling: A Multidisciplinary Journal, 9(2), 327-346. https://doi.org/10.1207/S15328007SEM0903

DiStefano, C., Liu, J., Jiang, N., \& Shi, D. (2018). Examination of the Weighted Root Mean Square Residual: Evidence for Trustworthiness? Structural Equation Modeling, 25(3), 453-466. https://doi.org/10.1080/10705511.2017.1390394

Dolan, C. V. (1994). Factor analysis of variables with 2, 3, 5 and 7 response categories: A 
comparison of categorical variable estimators using simulated data. British Journal of Mathematical and Statistical Psychology, 47, 309-326.

Dopp, V. (2013). Zum Einfluss des regulatorischen Fokus auf das Verhalten und Erleben von Stress in Konfliktsituationen [Universität Wien]. http://othes.univie.ac.at/29971/

Eid, M., \& Diener, E. F. (2001). Norms for experiencing emotions in different cultures: interand intranational differences. Journal of Personality and Social Psychology, 81(5), 869885. https://doi.org/10.1037/0022-3514.81.5.869

Elliot, A. J., \& Thrash, T. M. (2002). Approach-avoidance motivation in personality: Approach and avoidance temperaments and goals. Journal of Personality and Social Psychology, 82(5), 804-818. https://doi.org/10.1037/0022-3514.82.5.804

Fergus, T. A., \& Bardeen, J. R. (2016). Negative mood regulation expectancies moderate the association between happiness emotion goals and depressive symptoms. Personality and Individual Differences, 100, 23-27. https://doi.org/10.1016/j.paid.2015.08.010

Field, A., Miles, J., \& Field, Z. (2012). Discovering Statistics Using R. In Statistics (Vol. 58). https://doi.org/10.1111/insr.12011_21

Fletcher, T. D. (2012). QuantPsyc: Quantitative Psychology Tools (1.5). https://cran.rproject.org/package $=$ QuantPsyc

Ford, B. Q., Dmitrieva, J. O., Heller, D., Chentsova-Dutton, Y., Grossmann, I., Tamir, M., Uchida, Y., Koopmann-Holm, B., Floerke, V. A., Uhrig, M., Bokhan, T., \& Mauss, I. B. (2015). Culture shapes whether the pursuit of happiness predicts higher or lower wellbeing. Journal of Experimental Psychology: General, 144(6), 1053-1062. https://doi.org/10.1037/xge0000108

Ford, B. Q., Lam, P., John, O. P., \& Mauss, I. B. (2018). The psychological health benefits of accepting negative emotions and thoughts: Laboratory, diary, and longitudinal evidence. Journal of Personality and Social Psychology, 115(6), 1075-1092.

Ford, B. Q., \& Mauss, I. B. (2014). The Paradoxical Effects of Pursuing Positive Emotion. In Positive Emotion: Integrating the Light Sides and Dark Sides (pp. 363-381). https://doi.org/10.1093/acprof:oso/9780199926725.003.0020

Ford, B. Q., Mauss, I. B., \& Gruber, J. (2015). Valuing happiness is associated with bipolar disorder. Emotion, 15(2), 211-222. https://doi.org/10.1037/emo0000048

Fox, J., \& Weisberg, S. (2011). An R companion to applied regression. Sage. http://socserv.socsci.mcmaster.ca/jfox/Books/Companion

Fredrickson, B. L. (2013). Positive Emotions Broaden and Build. In P. Devine \& A. Plant (Eds.), Advances in Experimental Social Psychology (Vol. 47, pp. 1-53). Academic Press. https://doi.org/10.1016/B978-0-12-407236-7.00001-2

Gentzler, A. L., Palmer, C. A., Ford, B. Q., Moran, K. M., \& Mauss, I. B. (2019). Valuing happiness in youth: Associations with depressive symptoms and well-being. Journal of Applied Developmental Psychology, 62(February), 220-230. https://doi.org/10.1016/j.appdev.2019.03.001

George, L. S., \& Park, C. L. (2017). The Multidimensional Existential Meaning Scale: A tripartite approach to measuring meaning in life. The Journal of Positive Psychology, 12(6), 613-627. https://doi.org/10.1080/17439760.2016.1209546

Glaesmer, H., Grande, G., Braehler, E., \& Roth, M. (2011). The German version of the 
Satisfaction With Life Scale (SWLS). European Journal of Psychological Assessment, 27(2), 127-132. https://doi.org/10.1027/1015-5759/a000058

Gollwitzer, P. M., \& Sheeran, P. (2006). Implementation intentions and goal achievement: A meta-analysis of effects and processess. Advances in Experimental Social Psychology, $38,69-119$.

Goretzko, D., Pham, T. T. H., \& Bühner, M. (2019). Exploratory factor analysis: Current use, methodological developments and recommendations for good practice. Current Psychology, 2(Jöreskog 1967). https://doi.org/10.1007/s12144-019-00300-2

Gray, J. A. (1990). Brain Systems that Mediate both Emotion and Cognition. Cognition and Emotion, 4(3), 269-288. https://doi.org/10.1080/02699939008410799

Gross, J. J., \& John, O. P. (2003). Individual differences in two emotion regulation processes: Implications for affect, relationships, and well-being. Journal of Personality and Social Psychology, 85(2), 348-362. https://doi.org/10.1037/0022-3514.85.2.348

Grossmann, I., Karasawa, M., Kan, C., \& Kitayama, S. (2014). A cultural perspective on emotional experiences across the life span. Emotion, 14(4), 679-692. https://doi.org/10.1037/a0036041

Gruber, J., Mauss, I. B., \& Tamir, M. (2011). A dark side of happiness? How, when, and why happiness is not always good. Perspectives on Psychological Science, 6(3), 222-233. https://doi.org/10.1177/1745691611406927

Haase, C. M., Poulin, M. J., \& Heckhausen, J. (2012). Happiness as a motivator: Positive affect predicts primary control striving for career and educational goals. Personality and Social Psychology Bulletin, 38(8), 1093-1104. https://doi.org/10.1177/0146167212444906

Hartig, J., \& Moosbrugger, H. (2003). Die “ARES-Skalen” zur Erfassung der individuellen BIS- und BAS-Sensitivität: Entwicklung einer Lang- und einer Kurzfassung. Zeitschrift Für Differentielle Und Diagnostische Psychologie, 24(4), 293-310. https://doi.org/10.1024//0170-1789.24.4.293

Hayes, S. C. (2016). Acceptance and commitment therapy, relational frame theory, and the third wave of behavioral and cognitive therapies - Republished article. Behavior Therapy, 47(6), 869-885. https://doi.org/10.1016/j.beth.2016.11.006

Henderson, L. W., \& Knight, T. (2012). Integrating the hedonic and eudaimonic perspectives to more comprehensively understand wellbeing and pathways to wellbeing.

International Journal of Wellbeing, 2(3), 196-221. https://doi.org/doi:10.5502/ijw.v2i3.3

Higgins, E. T. (1997). Beyond pleasure and pain. American Psychologist, 52(12), 1280-1300. https://doi.org/10.1037//0003-066X.52.12.1280

Hofmann, S. G., \& Asmundson, G. J. G. (2008). Acceptance and mindfulness-based therapy: New wave or old hat? Clinical Psychology Review, 28(1), 1-16. https://doi.org/10.1016/j.cpr.2007.09.003

Horn, J. L. (1965). A rationale and test for the number of factors in factor analysis. Psychometrika, 30(2), 179-185. https://doi.org/10.1007/BF02289447

Howell, A. J., Passmore, H. A., \& Holder, M. D. (2016). Implicit Theories of Well-Being Predict Well-Being and the Endorsement of Therapeutic Lifestyle Changes. Journal of 
Happiness Studies, 17(6), 2347-2363. https://doi.org/10.1007/s10902-015-9697-6

Hsee, C. K., \& Hastie, R. (2006). Decision and experience: Why don't we choose what makes us happy? Trends in Cognitive Sciences, 10(1), 31-37. https://doi.org/10.1016/j.tics.2005.11.007

Hu, L.-T., \& Bentler, P. M. (1995). Evaluating model fit. In R. H. Hoyle (Ed.), Structural equation modeling: Concepts, issues, and applications (pp. 76-99). Sage.

Hunter, J. E., \& Hamilton, M. A. (2002). The Advantages of Using Standardized Scores in Causal Analysis. Human Communication Research, 28(4), 552-561. https://doi.org/10.1093/hcr/28.4.552

Huta, V., \& Ryan, R. M. (2010). Pursuing pleasure or virtue: The differential and overlapping well-being benefits of hedonic and eudaimonic motives. Journal of Happiness Studies, 11(6), 735-762. https://doi.org/10.1007/s10902-009-9171-4

Intelisano, S., Krasko, J., \& Luhmann, M. (2019). Integrating philosophical and psychological accounts of happiness and well-being. Journal of Happiness Studies, 21(1), 161-200. https://doi.org/10.1007/s10902-019-00078-x

Jackson, D. N. (1970). A sequential system for personality scale development. In Current topics in clinical and community psychology (Vol. 2, pp. 61-96). Elsevier.

Joshanloo, M. (2013). The influence of fear of happiness beliefs on responses to the satisfaction with life scale. Personality and Individual Differences, 54(5), 647-651. https://doi.org/10.1016/j.paid.2012.11.011

Joshanloo, M. (2014). Eastern conceptualizations of happiness: Fundamental differences with western views. Journal of Happiness Studies, 15(2), 475-493. https://doi.org/10.1007/s10902-013-9431-1

Joshanloo, M. (2017). Mediators of the relationship between externality of happiness and subjective well-being. Personality and Individual Differences, 119, 147-151. https://doi.org/10.1016/j.paid.2017.07.017

Joshanloo, M. (2019). Lay conceptions of happiness: Associations with reported well-being, personality traits, and materialism. Frontiers in Psychology, 10. https://doi.org/10.3389/fpsyg.2019.02377

Joshanloo, M., \& Weijers, D. (2013). Aversion to happiness across cultures: A review of where and why people are averse to happiness. Journal of Happiness Studies, 15(November 2015), 717-735. https://doi.org/10.1007/s10902-013-9489-9

Kämpfe, N., \& Mitte, K. (2009). What you wish is what you get? The meaning of individual variability in desired affect and affective discrepancy. Journal of Research in Personality, 43(3), 409-418. https://doi.org/10.1016/j.jrp.2009.01.007

Kesebir, P., \& Diener, E. F. (2008). In pursuit of happiness: Empirical answers to philosophical questions. Perspectives on Psychological Science, 3(2), 117-125. https://doi.org/10.1111/j.1745-6916.2008.00069.x

Keyes, C. L. M., Shmotkin, D., \& Ryff, C. D. (2002). Optimizing well-being: The empirical encounter of two traditions. Journal of Personality and Social Psychology, 82(6), 1007 1022. https://doi.org/10.1037//0022-3514.82.6.1007

King, L. A., \& Napa, C. K. (1998). What makes life good? Journal of Personality and Social Psychology, 75(1), 156-165. https://doi.org/10.1037/0022-3514.75.1.156 
Koole, S. L., \& Jostmann, N. B. (2004). Getting a grip on your feelings: Effects of action orientation and external demands on intuitive affect regulation. Journal of Personality and Social Psychology, 87(6), 974-990. https://doi.org/10.1037/0022-3514.87.6.974

Krasko, J., Intelisano, S., \& Luhmann, M. (2020). The Complexity of Lay Definitions of Happiness and Well-Being. Unpublished Manuscript in Preparation.

Krohne, W. H., Egloff, B., Kohlmann, C.-W., \& Tausch, A. (1996). Untersuchungen mit einer deutschen Version der" Positive and Negative Affect Schedule'(PANAS). Diagnostica, 42(2), 139-156. http://doi.apa.org/psycinfo/1996-05083-003

Kuhl, J. (1984). Volitional aspects of achievement motivation and learned helplessness: toward a comprehensive theory of action control. Progress in Experimental Personality Research. https://doi.org/10.1016/B978-0-12-541413-5.50007-3

Kuhl, J. (2000). A functional-design approach to motivation and self-regulation: The dynamics of personality systems interactions. In Handbook of self-regulation (pp. 111169). Academic Press.

Li, C. H. (2016). Confirmatory factor analysis with ordinal data: Comparing robust maximum likelihood and diagonally weighted least squares. Behavior Research Methods, 48(3), 936-949. https://doi.org/10.3758/s13428-015-0619-7

Linley, P. A., Maltby, J., Wood, A. M., Osborne, G., \& Hurling, R. (2009). Measuring happiness: The higher order factor structure of subjective and psychological well-being measures. Personality and Individual Differences, 47(8), 878-884. https://doi.org/10.1016/j.paid.2009.07.010

Lischetzke, T., \& Eid, M. (2003). Is attention to feelings beneficial or detrimental to affective well-being? Mood regulation as a moderator variable. Emotion, 3(4), 361-377. https://doi.org/10.1037/1528-3542.3.4.361

Lockwood, P., Jordan, C. H., \& Kunda, Z. (2002). Motivation by positive or negative role models: Regulatory focus determines who will best inspire us. Journal of Personality and Social Psychology, 83(4), 854-864. https://doi.org/10.1037/0022-3514.83.4.854

Lord, F. (1952). A theory of test scores. Psychometric Monographs, 7, 84. https://doi.org/10.1039/tf9524800166

Lubke, G. H., \& Muthén, B. O. (2004). Applying multigroup confirmatory factor models for continuous outcomes to likert scale data complicates meaningful group comparisons. Structural Equation Modeling: A Multidisciplinary Journal, 11(4), 583-514-534. https://doi.org/10.1207/s15328007sem1104_2

Luhmann, M., Necka, E. A., Schönbrodt, F. D., \& Hawkley, L. C. (2016). Is valuing happiness associated with lower well-being? A factor-level analysis using the Valuing Happiness Scale. Journal of Research in Personality, 60, 46-50.

https://doi.org/10.1016/j.jrp.2015.11.003

Luong, G., Wrzus, C., Wagner, G. G., \& Riediger, M. (2016). When bad moods may not be so bad: Valuing negative affect is associated with weakened affect - health links. Emotion, 16(3), 387-401. https://doi.org/10.1037/emo0000132

MacCallum, R. C. (2003). Working with imperfect models. Multivariate Behavioral Research, 38(1), 113-139. https://doi.org/10.1207/S15327906MBR3801

MacCallum, R. C., Widaman, K. F., Zhang, S., \& Hong, S. (1999). Sample size in factor 
analysis. Psychological Methods, 4(1), 84-99. https://doi.org/10.1037//1082-989x.4.1.84

Martin, M. W. (2008). Paradoxes of happiness. Journal of Happiness Studies, 9(2), 171-184. https://doi.org/10.1007/s10902-007-9056-3

Mauss, I. B., Savino, N. S., Anderson, C. L., Weisbuch, M., Tamir, M., \& Laudenslager, M. L. (2012). The pursuit of happiness can be lonely. Emotion, 12(5), 908-912. https://doi.org/10.1037/a0025299

Mauss, I. B., Tamir, M., Anderson, C. L., \& Savino, N. S. (2011). Can seeking happiness make people unhappy? Paradoxical effects of valuing happiness. Emotion, 11(4), 807815. https://doi.org/10.1037/a0022010

McGuirk, L., Kuppens, P., Kingston, R., \& Bastian, B. (2018). Does a culture of happiness increase rumination over failure? Emotion, 18(5), 755-764.

https://doi.org/10.1037/emo0000322

McMahan, E. A., \& Estes, D. (2011). Measuring lay conceptions of well-being: The Beliefs About Well-Being Scale. Journal of Happiness Studies, 12(2), 267-287. https://doi.org/10.1007/s10902-010-9194-x

Meade, A. W., \& Craig, S. B. (2012). Identifying careless responses in survey data. Psychological Methods, 17(3), 437-455. https://doi.org/10.1037/a0028085

Muthén, B. O., \& Asparouhov, T. (2002). Latent Variable Analysis With Categorical Outcomes: Multiple-Group And Growth Modeling In Mplus. Mplus Web Notes: No. 4, $0-22$.

Nikitin, J., \& Freund, A. M. (2010). When wanting and fearing go together: The effect of cooccurring social approach and avoidance motivation on behavior, affect, and cognition. European Journal of Social Psychology, 40, 783-804. https://doi.org/10.1002/ejsp

Oettingen, G., Pak, H., \& Schnetter, K. (2001). Self-regulation of goal-setting: Turning free fantasies about the future into binding goals. Journal of Personality and Social Psychology, 80(5), 736-753. https://doi.org/10.1037/0022-3514.80.5.736

Oishi, S., Graham, J., Kesebir, S., \& Galinha, I. C. (2013). Concepts of happiness across time and cultures. Personality and Social Psychology Bulletin, 39(5), 559-577. https://doi.org/10.1177/0146167213480042

Peterson, C., Park, N., \& Seligman, M. E. P. (2005). Orientations to happiness and life satisfaction: The full life versus the empty life. Journal of Happiness Studies, 6(1), 2541. https://doi.org/10.1007/s10902-004-1278-z

Pflug, J. (2009). Folk theories of happiness: A cross-cultural comparison of conceptions of happiness in Germany and South Africa. Social Indicators Research, 92(3), 551-563. https://doi.org/10.1007/s11205-008-9306-8

Pollock, N. C., Noser, A. E., Holden, C. J., \& Zeigler-Hill, V. (2016). Do orientations to happiness mediate the associations between personality traits and subjective wellbeing ? Journal of Happiness Studies, 17(2), 713-726. https://doi.org/10.1007/s10902015-9617-9

R Development Core Team. (2008). R: A language and environment for statistical computing. In R Foundation for Statistical Computing, Vienna, Austria. http://www.rproject.org

Rahm, T., Heise, E., \& Schuldt, M. (2017). Measuring the frequency of emotions-validation 
of the Scale of Positive and Negative Experience (SPANE) in Germany. PLoS ONE, 12(2), e0171288. https://doi.org/10.1371/journal.pone.0171288

Rammstedt, B., Kemper, C. J., Beierlein, C., \& Kovaleva, A. (2012). Eine kurze Skala zur Messung der fünf Dimensionen der Persönlichkeit: Big-Five-Inventory-10 (BFI-10). GESIS Working Paper, 23(2), 1-32. https://doi.org/10.12758/mda.2013.013

Revelle, W. (2017). psych: Procedures for personality and psychological research. Northwestern University. https://cran.r-project.org/package $=$ psych Version $=1.7 .8$

Risch, A. K., Strohmayer, C., \& Stangier, U. (2005). Psychologische WohlbefindensskalaPWS. Unpublished Manuscript.

Rosseel, Y. (2012). lavaan: An R package for structural equation modeling. Journal of Statistical Software, 48(2), 1-36. https://doi.org/10.18637/jss.v048.i02

Ruch, W., Harzer, C., Proyer, R. T., Park, N., \& Peterson, C. (2010). Ways to happiness in German-speaking countries: The adaptation of the German version of the Orientations to Happiness Questionnaire in paper-pencil and internet samples. European Journal of Psychological Assessment, 26(3), 227-234. https://doi.org/10.1027/1015-5759/a000030

Ryff, C. D. (1989). Happiness is everything, or is it? Explorations on the meaning of psychological well-being. Journal of Personality \& Social Psychology, 57(6), 10691081. https://doi.org/10.1037//0022-3514.57.6.1069

Sass, D. A., Schmitt, T. A., \& Marsh, H. W. (2014). Evaluating Model Fit With Ordered Categorical Data Within a Measurement Invariance Framework: A Comparison of Estimators. Structural Equation Modeling, 21(2), 167-180. https://doi.org/10.1080/10705511.2014.882658

Satorra, A. (2000). Scaled and adjusted restricted tests in multi-sample analysis of moment structures. In R. D. H. Heijmans, D. S. G. Pollock, \& A. Satorra (Eds.), Innovations in multivariate statistical analysis. A Festschrift for Heinz Neudecker (pp. 233-247). Kluwer Academic Publishers.

Schermelleh-Engel, K., Moosbrugger, H., \& Müller, H. (2003). Evaluating the fit of structural equation models: Tests of significance and descriptive goodness-of-fit measures. Methods of Psychological Research Online, 8(2), 23-74. https://doi.org/10.1002/0470010940

Schimmack, U., Oishi, S., \& Diener, E. F. (2002). Cultural influences on the relation between pleasant emotions and unpleasant emotions: Asian dialectic philosophies or individualism-collectivism? Cognition \& Emotion, 16(6), 705-719. https://doi.org/10.1080/02699930143000590

Schimmack, U., Radhakrishnan, P., Oishi, S., \& Dzokoto, V. (2002). Culture, personality, and subjective well-being: Integrating process models of life satisfaction. Personality Processes and Individual Differences, 82(4), 582-593. https://doi.org/10.1037//00223514.82.4.582

Schmutte, P. S., \& Ryff, C. D. (1997). Personality and well-being: Reexamining methods and meanings. Journal of Personality and Social Psychology, 73(3), 549-559. https://doi.org/10.1037/0022-3514.73.3.549

Schönbrodt, F. D., \& Perugini, M. (2013). At what sample size do correlations stabilize? Journal of Research in Personality, 47(5), 609-612. 
https://doi.org/10.1016/j.jrp.2013.05.009

Schooler, J. W., Ariely, D., \& Loewenstein, G. (2003). The pursuit and assessment of happiness can be self-defeating. In I. Brocas \& J. D. Carrillo (Eds.), The psychology of economic decisions: Vol. 1. Rationality and well-being (pp. 41-70). Oxford University Press.

Schwarz, G. (1978). Estimating the dimension of a model. The Annals of Statistics, 6(2), 461-464. https://doi.org/10.1214/aos/1176344136

Sin, N. L., \& Lyubomirsky, S. (2009). Enhancing well-being and alleviating depressive symptoms with positive psychology interventions: A practice-friendly meta-analysis. Journal of Clinical Psychology, 65(5), 467-487. https://doi.org/10.1002/jclp

Smederevac, S., Mitrović, D., Čolović, P., \& Nikolašević, Ž. (2014). Validation of the Measure of Revised Reinforcement Sensitivity Theory Constructs. Journal of Individual Differences, 35(1), 12-21. https://doi.org/10.1027/1614-0001/a000121

Soto, C. J. (2015). Is happiness good for your personality? Concurrent and prospective relations of the big five with subjective well-being. Journal of Personality, 83(1), 4555. https://doi.org/10.1111/jopy.12081

Soto, C. J., \& John, O. P. (2016). Short and extra-short forms of the Big Five Inventory-2: The BFI-2-S and BFI-2-XS. Journal of Research in Personality, 68, 69-81. https://doi.org/10.1016/j.jrp.2017.02.004

Steel, P., Taras, V., Uggerslev, K., \& Bosco, F. (2018). The happy culture: A theoretical, meta-analytic, and empirical review of the relationship between culture and wealth and subjective well-being. Personality and Social Psychology Review, 22(2), 128-169. https://doi.org/10.1177/1088868317721372

Steiger, J. H. (1990). Some additional thoughts on components, factors, and factor indeterminancy. Multivariate Behavioral Research, 25(1), 41-45. https://doi.org/10.1207/s15327906mbr2501_4

Stevens, J. P. (2002). Applied multivariate statistics for the social sciences (4th ed.). Lawrence Erlbaum Associates Publishers. https://doi.org//10.4324/9780203843130

Stoeber, J., \& Otto, K. (2006). Positive conceptions of perfectionism: Approaches, evidence, challenges. Personality And, 10(4), 295-319.

Stricker, J., Buecker, S., Schneider, M., \& Preckel, F. (2019). Multidimensional perfectionism and the big five personality traits: A meta-analysis. European Journal of Personality, 33(2), 176-196. https://doi.org/10.1002/per.2186

Strobel, A., Beauducel, A., Debener, S., \& Brocke, B. (2001). Eine deutschsprachige Version des BIS/BAS-Fragebogens von Carver und White. Zeitschrift Für Differentielle Und Diagnostische Psychologie, 22(3), 216-227. https://doi.org/http://dx.doi.org/10.1024//0170-1789.22.3.216

Tamir, M. (2009). Differential preferences for happiness: Extraversion and trait-consistent emotion regulation. Journal of Personality, 77(2), 447-470. https://doi.org/10.1111/j.1467-6494.2008.00554.x

Tkach, C., \& Lyubomirsky, S. (2006). How do people pursue happiness?: Relating personality, happiness-increasing strategies, and well-being. Journal of Happiness Studies, 7(2), 183-225. https://doi.org/10.1007/s10902-005-4754-1 
Tov, W. (2018). Well-being concepts and components. In E. F. Diener, S. Oishi, \& L. Tay (Eds.), Handbook of well-being. DEF Publishers. https://doi.org/nobascholar.com Uchida, Y., \& Ogihara, Y. (2012). Personal or interpersonal construal of happiness: A cultural psychological perspective. International Journal of Wellbeing, 2(4), 354-369. https://doi.org/10.5502/ijw.v2.i4.5

Updegraff, J. A., Gable, S. L., \& Taylor, S. E. (2004). What makes experiences satisfying? The interaction of approach-avoidance motivations and emotions in well-being. Journal of Personality and Social Psychology, 86(3), 496-504. https://doi.org/10.1037/00223514.86.3.496

Watson, D., Clark, L. A., \& Tellegen, A. (1988). Development and validation of brief measures of positive and negative affect: the PANAS scales. Journal of Personality and Social Psychology, 54(6), 1063-1070. https://doi.org/10.1037/0022-3514.54.6.1063

Wolf, E. J., Harrington, K. M., Clark, S. L., \& Miller, M. W. (2013). Sample size requirements for structural equation models: An evaluation of power, bias, and solution propriety. Educational and Psychological Measurement, 73(6), 913-934.

https://doi.org/10.1177/0013164413495237 


\section{Appendix}

\section{The Happiness Goal Orientations Scale: German version}

Instruktion: Bitte geben Sie an, wie sehr die folgenden Aussagen auf Sie zutreffen.

Antwortformat: 1 (trifft überhaupt nicht zu) - 5 (trifft voll und ganz zu)

1. Ich strenge mich besonders an, um glücklich zu sein.

2. Ich scheue keine Mühen um zu verhindern, unglücklich zu sein.

3. Ich tue alles dafür um zu verhindern, unglücklich zu sein.

4. Ich überwinde oft Hürden, um glücklich zu werden.

5. Ich versuche aktiv glücklich zu werden.

6. Ich mache mir oft Sorgen, dass ich in der Zukunft unglücklich sein könnte.

7. Ich habe Angst davor, unglücklich zu sein.

8. Ich achte mehr auf Bedrohungen als auf erfreuliche Ereignisse.

9. Ich mache mir viele Sorgen darüber, dass es mir nicht gelingen könnte, glücklich zu sein.

10. Ich sehe häufig davon ab, etwas zu tun, weil ich Angst habe, dass es mich unglücklich machen könnte.

Subskalen: Bemühtes Streben nach Glück (1-5), Besorgt über Unglück (6-10)

\section{The Happiness Goal Orientations Scale: English version}

Instruction: Please indicate, to what extend you agree with the following statements. Response format: 1 (does not apply) - 5 (applies completely)

1. I try very hard to be happy.

2. I go out of my way to avoid being unhappy.

3. I do everything I can to avoid being unhappy.

4. I often overcome challenges to become happy.

5. I actively try to become happy.

6. I am often worried that I might be unhappy in the future.

7. I am scared of being unhappy.

8. I focus more on threats than on pleasant events.

9. I worry a lot that I might not succeed in being happy.

10. I often refrain from doing something because I am scared that it might make me unhappy.

Subscales: Happiness-Related Strivings (1-5), Happiness-Related Concerns (6-10) 


\section{Tables}

Table 1. Psychometric properties for the initial 14-item solution in Study 1.

\begin{tabular}{|c|c|c|c|c|c|c|c|}
\hline $\begin{array}{l}\text { Item } \\
\text { No. }\end{array}$ & $\begin{array}{c}\text { Mean } \\
\text { (item difficulties) }\end{array}$ & SD & $\begin{array}{c}\alpha \text { when Item is } \\
\text { dropped } \\
\text { (two-factor } \\
\text { model) }\end{array}$ & Skewness & Kurtosis & $\begin{array}{c}\text { Item whole } \\
\text { correlation } \\
\text { (discriminatory } \\
\text { power) }\end{array}$ & $\begin{array}{l}\text { Corrected } \\
\text { item whole } \\
\text { correlation }\end{array}$ \\
\hline 4 & 2.51 & 1.05 & .80 & 0.33 & -0.56 & .61 & .63 \\
\hline 15 & 2.45 & 1.13 & .79 & 0.46 & -0.62 & .70 & .63 \\
\hline 14 & 2.65 & 1.17 & .79 & 0.24 & -0.83 & .67 & .60 \\
\hline 3 & 3.13 & 1.27 & .80 & -0.08 & -1.12 & .67 & .57 \\
\hline 18 & 2.85 & 1.32 & .75 & 0.16 & -1.32 & .83 & .82 \\
\hline 13 & 3.16 & 1.31 & .77 & -0.03 & -1.27 & .79 & .76 \\
\hline 10 & 3.17 & 1.12 & .82 & -0.27 & -0.75 & .52 & .39 \\
\hline 7 & 3.47 & 1.00 & .72 & -0.34 & -0.39 & .61 & .52 \\
\hline 9 & 3.16 & 0.90 & .73 & -0.06 & -0.42 & .58 & .48 \\
\hline 26 & 3.01 & 1.05 & .73 & $>-0.01$ & -0.76 & .61 & .50 \\
\hline 27 & 3.17 & 1.00 & .71 & -0.14 & -0.52 & .65 & .55 \\
\hline 23 & 3.06 & 0.93 & .71 & -0.11 & -0.28 & .64 & .57 \\
\hline 19 & 2.68 & 0.93 & .69 & 0.19 & -0.02 & .71 & .66 \\
\hline 5 & 2.90 & 0.99 & .72 & 0.08 & -0.45 & .62 & .52 \\
\hline
\end{tabular}


Table 2. Standardized factor loadings in exploratory factor analyses of Study 1 using Maximum Likelihood estimation, interfactor correlations, explained variances, and fit statistics.

\begin{tabular}{|c|c|c|c|c|c|c|}
\hline \multirow[b]{2}{*}{ Item No. } & \multirow[b]{2}{*}{ Item wording } & \multicolumn{2}{|c|}{ Two-Factor Model } & \multicolumn{3}{|c|}{ Three-Factor Model } \\
\hline & & Factor 1 & Factor 2 & Factor 1 & Factor 2 & Factor 3 \\
\hline 4 & $\begin{array}{l}\text { I am more oriented in avoiding unhappiness than in } \\
\text { achieving happiness. }\end{array}$ & .52 & -.01 & .19 & -.11 & .52 \\
\hline 15 & $\begin{array}{l}\text { I often refrain from doing something because I am scared } \\
\text { that it might make me unhappy. }\end{array}$ & .67 & -.10 & .53 & -.10 & .20 \\
\hline 14 & I focus more on threats than on pleasant events. & .64 & -.14 & .35 & -.22 & .46 \\
\hline 3 & I am scared of being unhappy. & .51 & .14 & .56 & .19 & -.06 \\
\hline 18 & I worry a lot that I might not succeed in being happy. & .87 & -.09 & .94 & -.02 & -.08 \\
\hline 13 & I am often worried that I might be unhappy in the future. & .84 & -.09 & .80 & -.04 & .02 \\
\hline 7 & I actively try to become happy. & -.26 & .65 & -.06 & .68 & -.21 \\
\hline 9 & I often overcome challenges to become happy. & -.03 & .47 & -.01 & .45 & .05 \\
\hline 26 & $\begin{array}{l}\text { Generally, I am focused on avoiding negative things in } \\
\text { my life. }\end{array}$ & .34 & .36 & -.07 & .24 & .72 \\
\hline 27 & I pursue some goals to not become unhappy. & .22 & .46 & .14 & .41 & .19 \\
\hline 23 & I try very hard to be happy. & .00 & .61 & .22 & .69 & -.25 \\
\hline 19 & I go out of my way to avoid being unhappy. & .00 & .65 & -.16 & .56 & .36 \\
\hline 5 & I do everything I can to avoid being unhappy. & -.04 & .54 & -.07 & .48 & .14 \\
\hline 10 & If I feel unhappy, I get insecure and nervous. & .31 & .16 & .23 & .14 & .15 \\
\hline \multicolumn{2}{|c|}{ Correlation with factor 1} & - & .37 & - & .23 & .55 \\
\hline \multicolumn{2}{|c|}{ Correlation with factor 2} & - & - & - & - & .28 \\
\hline \multicolumn{2}{|l|}{$R^{2}$} & .22 & .15 & .18 & .15 & .11 \\
\hline \multicolumn{2}{|l|}{$\chi^{2}(\mathrm{df})$} & \multicolumn{2}{|c|}{$143.37(64)$} & \multicolumn{3}{|c|}{$60.74(52)$} \\
\hline \multicolumn{2}{|l|}{$\mathrm{BIC}$} & \multicolumn{2}{|c|}{-200.94} & \multicolumn{3}{|c|}{219.01} \\
\hline \multicolumn{2}{|l|}{ TLI } & \multicolumn{2}{|c|}{.86} & \multicolumn{3}{|c|}{.98} \\
\hline \multicolumn{2}{|l|}{ RMSEA } & \multirow{2}{*}{\multicolumn{2}{|c|}{$\begin{array}{c}.08 \\
05 \cdot .09\end{array}$}} & \multicolumn{3}{|c|}{.03} \\
\hline \multicolumn{2}{|l|}{$[90 \% \mathrm{CI}]$} & & & \multicolumn{3}{|c|}{$[00 ; .05]$} \\
\hline
\end{tabular}

Notes. $\mathrm{df}=$ degrees of freedom. $\mathrm{CI}=$ confidence interval. 
Table 3. Descriptive statistics and Cronbach's alphas of Study 2a and 2b.

\begin{tabular}{lccc}
\hline \multicolumn{1}{c}{ Scale } & $M$ & $S D$ & $\alpha$ \\
\hline Study 2a & & & \\
Happiness Goal Orientations & & & \\
$\quad$ Happiness-Related Strivings & 3.03 & 0.73 & .73 \\
$\quad$ Happiness-Related Concerns & 2.82 & 0.97 & .84 \\
Valuing Happiness Scale & & & \\
$\quad$ complete & 4.38 & 1.11 & .74 \\
Factor 1 & 5.03 & 1.34 & .78 \\
Factor 2 & 3.65 & 1.30 & .50 \\
Prioritizing positivity & 5.58 & 1.58 & .81 \\
Perceived expectancies to feel happiness & & & \\
self-evaluation & 4.28 & 2.34 & .73 \\
personal expectancies & 5.33 & 1.49 & .63 \\
$\quad$ social expectancies & 5.43 & 1.55 & .73 \\
BAS Drive & 2.93 & 0.79 & .78 \\
BAS Fun Seeking & 2.73 & 0.71 & .48 \\
BAS Reward Responsiveness & 3.20 & 0.89 & .82 \\
BIS & 2.92 & 0.80 & .86 \\
Prevention focus & 3.87 & 1.29 & .87 \\
Promotion focus & 4.70 & 1.09 & .86 \\
Mood repair & 2.78 & 0.69 & .89 \\
Mood maintenance & 2.95 & 0.68 & .82 \\
Emotion regulation & & & \\
reappraisal & 4.17 & 1.25 & .86 \\
$\quad$ suppression & 3.64 & 1.37 & .80 \\
Extraversion & 3.10 & 1.15 & .82 \\
Neuroticism & 3.01 & 1.02 & .65 \\
Life satisfaction & 4.48 & 1.47 & .90 \\
Positive affect & 3.64 & 0.87 & .84 \\
Negative affect & 2.54 & 1.03 & .83 \\
Study 2b & & & \\
Happiness Goal Orientations & & & \\
Happiness-Related Strivings & 3.07 & 0.72 & .70 \\
Happiness-Related Concerns & 2.56 & 1.04 & .87 \\
Extraversion & 3.11 & 0.75 & .53 \\
Neuroticism & 2.75 & 0.91 & .70 \\
Life satisfaction & 5.15 & 1.16 & .85 \\
Positive affect & 3.24 & 0.67 & .87 \\
Negative affect & 1.70 & 0.59 & .87 \\
Autonomy & 4.24 & 0.77 & .82 \\
Environmental mastery & 4.50 & 0.72 & .79 \\
Personal growth & 4.61 & 0.64 & .69 \\
Positive relations with others & 4.65 & 0.82 & .83 \\
Purpose in life & 4.50 & 0.77 & .79 \\
Self-acceptance & 4.36 & 0.84 & .85 \\
\hline$\quad$ & & & \\
& & & \\
\hline
\end{tabular}


Table 4. Standardized factor loadings in confirmatory factor analyses of Studies $2 \mathrm{a}$ and $2 \mathrm{~b}$ using Maximum Likelihood estimation, interfactor correlations, explained variances, and fit statistics.

\begin{tabular}{|c|c|c|c|c|c|c|c|c|c|c|}
\hline \multirow[b]{2}{*}{ Item No. } & \multicolumn{2}{|c|}{$\begin{array}{c}\text { Study 2a: } \\
\text { Two-Factor Model }\end{array}$} & \multicolumn{3}{|c|}{$\begin{array}{c}\text { Study 2a: } \\
\text { Three-Factor Model }\end{array}$} & \multicolumn{2}{|c|}{$\begin{array}{c}\text { Study 2b: } \\
\text { Two-Factor Model }\end{array}$} & \multicolumn{3}{|c|}{$\begin{array}{c}\text { Study 2b: } \\
\text { Three-Factor Model }\end{array}$} \\
\hline & Factor 1 & Factor 2 & Factor 1 & Factor 2 & Factor 3 & Factor 1 & Factor 2 & Factor 1 & Factor 2 & Factor 3 \\
\hline 4 & .57 & & & & .73 & .59 & & & & .72 \\
\hline 15 & .61 & & .60 & & & .75 & & .74 & & \\
\hline 14 & .62 & & & & .79 & .69 & & & & .85 \\
\hline 3 & .70 & & .70 & & & .74 & & .76 & & \\
\hline 18 & .82 & & .82 & & & .80 & & .81 & & \\
\hline 13 & .84 & & .85 & & & .82 & & .84 & & \\
\hline 7 & & .43 & & .47 & & & .56 & & .60 & \\
\hline 9 & & .47 & & .49 & & & .48 & & .50 & \\
\hline 26 & & .50 & & & .28 & & .26 & & & .25 \\
\hline 27 & & .53 & & .52 & & & .44 & & .42 & \\
\hline 23 & & .60 & & .63 & & & .66 & & .68 & \\
\hline 19 & & .67 & & .66 & & & .51 & & .49 & \\
\hline 5 & & .71 & & .68 & & & .61 & & .56 & \\
\hline Correlation with factor 1 & - & .37 & - & .36 & .74 & - & .19 & - & .18 & .76 \\
\hline Correlation with factor 2 & - & - & - & - & .24 & - & - & - & - & .03 \\
\hline \multicolumn{11}{|c|}{ Fit statistics of the original models } \\
\hline$\chi^{2}(\mathrm{df})$ & 318.3 & (64) & & $313.06(62$ & & 233 & $7(64)$ & & $187.20(6$ & 62) \\
\hline AIC & 170 & 3.41 & & 17002.13 & & & 3.38 & & 8990.8 & \\
\hline $\mathrm{BIC}$ & 171 & 5.07 & & 17122.06 & & & 7.58 & & 9092.0 & \\
\hline CFI & & & & .87 & & & 4 & & .88 & \\
\hline TLI & & & & .83 & & & 0 & & .85 & \\
\hline RMSEA & & & & .09 & & & 1 & & .09 & \\
\hline$[90 \% \mathrm{CI}]$ & {$[.08$} & 10] & & {$[.08 ; .10]$} & & & $.12]$ & & {$[.08 ; .11$} & \\
\hline SRMR & & & & .10 & & & 0 & & .09 & \\
\hline \multicolumn{11}{|c|}{ Fit statistics after exclusion of Items 4, 26, and 27} \\
\hline$\chi^{2}(\mathrm{df})$ & 147.4 & (34) & & & & 105 & $7(34)$ & & & \\
\hline AIC & 130 & 4.33 & & & & & 9.49 & & & \\
\hline $\mathrm{BIC}$ & 131 & 1.18 & & & & & 2.75 & & & \\
\hline CFI & & & & & & & 1 & & & \\
\hline TLI & & & & & & & 8 & & & \\
\hline RMSEA & & & & & & & 9 & & & \\
\hline$[90 \% \mathrm{CI}]$ & {$[.07$} & 10] & & & & & $.11]$ & & & \\
\hline SRMR & & & & & & & 8 & & & \\
\hline \multicolumn{11}{|c|}{ Fit statistics after consideration of correlations within factors } \\
\hline$\chi^{2}(\mathrm{df})$ & 97.3 & (29) & & & & 63. & (29) & & & \\
\hline AIC & 130 & 4.22 & & & & & 7.45 & & & \\
\hline $\mathrm{BIC}$ & 131 & 1.74 & & & & & 8.16 & & & \\
\hline CFI & & & & & & & 6 & & & \\
\hline TLI & & & & & & & 3 & & & \\
\hline RMSEA & & & & & & & 7 & & & \\
\hline$[90 \% \mathrm{CI}]$ & {$[.06$} & 09] & & & & & $.09]$ & & & \\
\hline SRMR & & & & & & & 7 & & & \\
\hline
\end{tabular}

Notes. $\mathrm{df}=$ degrees of freedom. $\mathrm{CI}=$ confidence interval. 
Table 5. Standardized factor loadings in confirmatory factor analyses of Studies $2 \mathrm{a}$ and $2 \mathrm{~b}$ using Weighted Least Squares Mean and Variance Adjusted estimation, interfactor correlations, explained variances, and fit statistics.

\begin{tabular}{|c|c|c|c|c|c|c|c|c|c|c|}
\hline \multirow{2}{*}{ Item No. } & \multicolumn{2}{|c|}{$\begin{array}{c}\text { Study 2a: } \\
\text { Two-Factor Model }\end{array}$} & \multicolumn{3}{|c|}{$\begin{array}{c}\text { Study 2a: } \\
\text { Three-Factor Model }\end{array}$} & \multicolumn{2}{|c|}{$\begin{array}{c}\text { Study 2b: } \\
\text { Two-Factor Model }\end{array}$} & \multicolumn{3}{|c|}{$\begin{array}{c}\text { Study 2b: } \\
\text { Three-Factor Model }\end{array}$} \\
\hline & Factor 1 & Factor 2 & Factor 1 & Factor 2 & Factor 3 & Factor 1 & Factor 2 & Factor 1 & Factor 2 & Factor 3 \\
\hline 4 & .66 & & & & .74 & .68 & & & & .76 \\
\hline 15 & .66 & & .67 & & & .80 & & .82 & & \\
\hline 14 & .68 & & & & .76 & .77 & & & & .87 \\
\hline 3 & .73 & & .75 & & & .79 & & .79 & & \\
\hline 18 & .84 & & .85 & & & .84 & & .84 & & \\
\hline 13 & .85 & & .86 & & & .87 & & .88 & & \\
\hline 7 & & .38 & & .38 & & & .50 & & .53 & \\
\hline 9 & & .47 & & .48 & & & .49 & & .51 & \\
\hline 26 & & .54 & & & .46 & & .40 & & & .35 \\
\hline 27 & & .62 & & .64 & & & .49 & & .49 & \\
\hline 23 & & .66 & & .68 & & & .69 & & .72 & \\
\hline 19 & & .70 & & .71 & & & .52 & & .53 & \\
\hline 5 & & .74 & & .73 & & & .71 & & .67 & \\
\hline \multicolumn{11}{|l|}{10} \\
\hline Correlation with factor 1 & - & .39 & - & .39 & .77 & - & .22 & - & .21 & .79 \\
\hline Correlation with factor 2 & - & - & - & - & .40 & - & - & - & - & .13 \\
\hline \multicolumn{11}{|c|}{ Fit statistics of the original models } \\
\hline$\chi^{2}(\mathrm{df})$ & \multicolumn{2}{|c|}{$502.95(64)$} & \multicolumn{3}{|c|}{$664.82(62)$} & \multicolumn{2}{|c|}{$314.51(64)$} & \multicolumn{3}{|c|}{$286.01(62)$} \\
\hline CFI & \multicolumn{2}{|c|}{.90} & \multicolumn{3}{|c|}{.86} & \multicolumn{2}{|c|}{.91} & \multicolumn{3}{|c|}{.92} \\
\hline TLI & \multicolumn{2}{|c|}{.88} & \multicolumn{3}{|c|}{.83} & \multicolumn{2}{|c|}{.88} & \multicolumn{3}{|c|}{.89} \\
\hline RMSEA & \multicolumn{2}{|c|}{.12} & \multicolumn{3}{|c|}{.15} & \multicolumn{2}{|c|}{.13} & \multicolumn{3}{|c|}{.12} \\
\hline$[90 \% \mathrm{CI}]$ & \multicolumn{2}{|c|}{$[.12 ; .13]$} & \multicolumn{3}{|c|}{$[.14 ; .16]$} & \multicolumn{2}{|c|}{$[.11 ; .14]$} & \multicolumn{3}{|c|}{$[.11 ; .14]$} \\
\hline WRMR & \multicolumn{2}{|c|}{1.88} & \multicolumn{3}{|c|}{2.11} & \multicolumn{2}{|c|}{1.57} & \multicolumn{3}{|c|}{1.46} \\
\hline
\end{tabular}

Fit statistics after exclusion of Items 4, 26, and 27

$\begin{array}{lcc}\chi^{2}(\mathrm{df}) & 238.75(34) & 140.25(34) \\ \mathrm{CFI} & .94 & .95 \\ \text { TLI } & .92 & .94 \\ \text { RMSEA } & .11 & .11 \\ {[90 \% \mathrm{CI}]} & {[.10 ; .13]} & {[.10 ; .13]} \\ \text { WRMR } & 1.54 & 1.22\end{array}$

Fit statistics after consideration of correlations within factors

\begin{tabular}{lcc}
$\chi^{2}(\mathrm{df})$ & $177.28(29)$ & $103.19(29)$ \\
CFI & .96 & .97 \\
TLI & .93 & .95 \\
RMSEA & .11 & .10 \\
{$[90 \% \mathrm{CI}]$} & {$[.09 ; .12]$} & {$[.08 ; .13]$} \\
WRMR & 1.30 & 1.05 \\
\hline
\end{tabular}

Notes. $\mathrm{df}=$ degrees of freedom. $\mathrm{CI}=$ confidence interval. 
Table 6. Bivariate correlations of Study 2a.

\begin{tabular}{|c|c|c|}
\hline & $\begin{array}{c}\text { Happiness-Related } \\
\text { Strivings }\end{array}$ & $\begin{array}{c}\text { Happiness-Related } \\
\text { Concerns }\end{array}$ \\
\hline Happiness-Related Strivings & - & $.20 * * *$ \\
\hline \multicolumn{3}{|l|}{ Valuing Happiness Scale } \\
\hline complete & $.35 * * *$ & $.34 * * *$ \\
\hline Factor 1 & $.33 * * *$ & .08 \\
\hline Factor 2 & $.30 * * *$ & $.31 * * *$ \\
\hline Prioritizing positivity & $.41 * * *$ & .06 \\
\hline \multicolumn{3}{|c|}{ Perceived expectancies to feel happiness } \\
\hline self-evaluation & .08 & $.48 * * *$ \\
\hline personal expectancies & $.28 * * *$ & $.10 *$ \\
\hline social expectancies & .05 & $.36 * * *$ \\
\hline BAS drive & $.20 * * *$ & $-.13 * *$ \\
\hline BAS reward responsiveness & $.11 *$ & $-.13 * *$ \\
\hline BAS fun seeking & .03 & $-.13 * *$ \\
\hline BIS & $.11 *$ & $.24 * * *$ \\
\hline Prevention focus & $.11 *$ & $.72 * * *$ \\
\hline Promotion focus & $.37 * * *$ & .08 \\
\hline Mood repair & .08 & $-.58 * * *$ \\
\hline Mood maintenance & $.12 *$ & $-.45 * * *$ \\
\hline \multicolumn{3}{|l|}{ Emotion regulation } \\
\hline reappraisal & $.25 * * *$ & $-.23 * * *$ \\
\hline suppression & $>-.01$ & $.22 * * *$ \\
\hline Extraversion & $.15^{* *}$ & $-.28 * * *$ \\
\hline Neuroticism & .02 & $.54 * * *$ \\
\hline Life satisfaction & $.12 * *$ & $-.43 * * *$ \\
\hline Positive affect & $.11 *$ & $-.44 * * *$ \\
\hline Negative affect & $>-.01$ & $.48 * * *$ \\
\hline Age & -.08 & $-.20 * * *$ \\
\hline Gender & -.09 & -.11 \\
\hline
\end{tabular}


Table 7. Multiple regression results for the prediction of Happiness-Related Strivings and Happiness-Related Concerns (Study 2a).

\begin{tabular}{|c|c|c|c|c|}
\hline & \multicolumn{2}{|c|}{$\begin{array}{l}\text { Happiness-Related } \\
\text { Strivings }\end{array}$} & \multicolumn{2}{|c|}{$\begin{array}{l}\text { Happiness-Related } \\
\text { Concerns }\end{array}$} \\
\hline & $\beta$ & $t(\mathrm{df}=436)$ & $\beta$ & $t(\mathrm{df}=436)$ \\
\hline \multicolumn{5}{|l|}{ Valuing Happiness Scale } \\
\hline Factor 1 & .02 & 0.24 & .03 & 0.78 \\
\hline Factor 2 & .09 & 1.61 & .05 & 1.31 \\
\hline Prioritizing positivity & $.21 * * *$ & 3.83 & .05 & 1.10 \\
\hline \multicolumn{5}{|l|}{$\begin{array}{l}\text { Perceived expectancies } \\
\text { to feel happiness }\end{array}$} \\
\hline self-evaluation & -.06 & -1.19 & .02 & 0.49 \\
\hline personal expectancies & $.15^{* *}$ & 3.30 & .01 & 0.43 \\
\hline social expectancies & .03 & 0.66 & .01 & 0.27 \\
\hline BAS drive & $.17^{* *}$ & 3.23 & .02 & 0.56 \\
\hline BAS reward responsiveness & -.04 & -0.68 & -.03 & -0.71 \\
\hline BIS & .01 & 0.19 & $>-.01$ & -0.08 \\
\hline BAS fun seeking & -.03 & -0.60 & -.05 & -1.43 \\
\hline Promotion focus & $.16^{* *}$ & 3.22 & -.05 & -1.32 \\
\hline Prevention focus & .08 & 1.36 & $.47 * * *$ & 10.53 \\
\hline Life satisfaction & .01 & 0.10 & -.04 & -0.98 \\
\hline Positive affect & .03 & 0.56 & -.05 & -0.97 \\
\hline Negative affect & .03 & 0.47 & .08 & 1.83 \\
\hline Mood repair & .06 & 0.99 & $-.19 * * *$ & -4.01 \\
\hline Mood maintenance & -.04 & -0.65 & -.01 & -0.33 \\
\hline \multicolumn{5}{|l|}{ Emotion regulation } \\
\hline reappraisal & $.11^{*}$ & 2.17 & -.04 & -0.95 \\
\hline suppression & $>-.01$ & -0.03 & .04 & 1.04 \\
\hline Extraversion & .08 & 1.67 & .07 & 1.87 \\
\hline \multirow[t]{2}{*}{ Neuroticism } & .06 & 1.09 & $.10^{*}$ & 2.36 \\
\hline & \multicolumn{2}{|c|}{$\begin{array}{c}R^{2}=.30 * * * \\
F(21,436)=8.89\end{array}$} & \multicolumn{2}{|c|}{$\begin{array}{c}R^{2}=.61^{* * *} \\
F(21,436)=32.93\end{array}$} \\
\hline
\end{tabular}

Notes. ${ }^{*} p<.05 .{ }^{* *} p<.01 .{ }^{* * *} p<.001 . \mathrm{df}=$ degrees of freedom. All variables are standardized. 
Table 8. Hierarchical multiple regression results of Study 2a for Happiness Goal Orientation dimensions predicting subjective well-being, controlling for age and gender, Valuing Happiness factors, extraversion, and neuroticism.

\begin{tabular}{|c|c|c|c|c|}
\hline & Value & Life Satisfaction & Positive Affect & Negative Affect \\
\hline Model $1(\mathrm{df}=454)$ & $R^{2}$ & .01 & $<.01$ & $.04^{* * *}$ \\
\hline \multirow[t]{2}{*}{ Age } & $\beta$ & $<.01$ & $>-.01$ & $-.01^{* *}$ \\
\hline & $95 \% \mathrm{CI}$ & $-.01, .01$ & $-.01, .01$ & $-.02,>-.01$ \\
\hline \multirow[t]{2}{*}{ Gender: male } & $\beta$ & $-.23^{*}$ & -.04 & $-.24^{*}$ \\
\hline & $95 \% \mathrm{CI}$ & $-.44,-.02$ & $-.25, .17$ & $-.44,-.03$ \\
\hline Model $2(\mathrm{df}=452)$ & $\Delta R^{2}$ & $.24^{* * *}$ & $.24^{* * *}$ & $.21^{* * *}$ \\
\hline \multirow[t]{2}{*}{ Age } & $\beta$ & -.01 & $-.01^{*}$ & -.01 \\
\hline & $95 \% \mathrm{CI}$ & $-.01,<.01$ & $-.02,>-.01$ & $-.01,<.01$ \\
\hline \multirow[t]{2}{*}{ Gender: male } & $\beta$ & $-.27^{* *}$ & -.09 & -.18 \\
\hline & $95 \% \mathrm{CI}$ & $-.46,-.09$ & $-.28, .09$ & $-.36, .01$ \\
\hline \multirow[t]{2}{*}{ Happiness-Related Strivings } & $\beta$ & $.21^{* * *}$ & $.19^{* * *}$ & $-.10^{*}$ \\
\hline & $95 \% \mathrm{CI}$ & $.13, .29$ & $.11, .27$ & $-.19,-.02$ \\
\hline \multirow[t]{2}{*}{ Happiness-Related Concerns } & $\beta$ & $-.50^{* * *}$ & $-.50^{* * *}$ & $.48^{* * *}$ \\
\hline & $95 \% \mathrm{CI}$ & $-.58,-.42$ & $-.59,-.42$ & $.40, .56$ \\
\hline Model $3(\mathrm{df}=450)$ & $\Delta R^{2}$ & $.02^{* *}$ & $.03^{* * *}$ & $<.01$ \\
\hline \multirow[t]{2}{*}{ Age } & $\beta$ & -.01 & $-.01^{*}$ & -.01 \\
\hline & $95 \% \mathrm{CI}$ & $-.01,<.01$ & $-.02,>-.01$ & $-.01,<.01$ \\
\hline \multirow[t]{2}{*}{ Gender: male } & $\beta$ & $-.22^{*}$ & -.03 & $-.20^{*}$ \\
\hline & $95 \% \mathrm{CI}$ & $-.40,-.04$ & $-.26, .15$ & $-.39,-.01$ \\
\hline \multirow[t]{2}{*}{ Happiness-Related Strivings } & $\beta$ & $.17^{* * *}$ & $.15^{* * *}$ & $-.10^{*}$ \\
\hline & $95 \% \mathrm{CI}$ & $.09, .26$ & $.06, .23$ & $-.19,-.01$ \\
\hline \multirow[t]{2}{*}{ Happiness-Related Concerns } & $\beta$ & $-.48^{* * *}$ & $-.47^{* * *}$ & $.46^{* * *}$ \\
\hline & $95 \% \mathrm{CI}$ & $-.56,-.39$ & $-.56,-.39$ & $.37, .55$ \\
\hline \multirow[t]{2}{*}{ Valuing Happiness Factor 1} & $\beta$ & $.19^{* * *}$ & $.22^{* * *}$ & -.06 \\
\hline & $95 \% \mathrm{CI}$ & $.09, .29$ & $.12, .32$ & $-.16, .04$ \\
\hline \multirow[t]{2}{*}{ Valuing Happiness Factor 2} & $\beta$ & -.10 & $-.12^{*}$ & .07 \\
\hline & $95 \% \mathrm{CI}$ & $-.20, .00$ & $-.22,-.01$ & $-.04, .17$ \\
\hline Model $4(\mathrm{df}=448)$ & $\Delta R^{2}$ & $.05^{* * *}$ & $.04^{* * *}$ & $.04^{* * *}$ \\
\hline \multirow[t]{2}{*}{ Age } & $\beta$ & -.01 & $-.01^{*}$ & -.01 \\
\hline & $95 \% \mathrm{CI}$ & $-.01,<.01$ & $-.02,>-.01$ & $-.01,<.01$ \\
\hline \multirow[t]{2}{*}{ Gender: male } & $\beta$ & $-.28^{* *}$ & -.08 & -.10 \\
\hline & $95 \% \mathrm{CI}$ & $-.46,-.10$ & $-.27, .10$ & $-.29, .09$ \\
\hline \multirow[t]{2}{*}{ Happiness-Related Strivings } & $\beta$ & $.12^{* *}$ & $.10^{*}$ & -.07 \\
\hline & $95 \% \mathrm{CI}$ & $.04, .21$ & $.02, .19$ & $-.15, .02$ \\
\hline \multirow[t]{2}{*}{ Happiness-Related Concerns } & $\beta$ & $-.35^{* * *}$ & $-.37^{* * *}$ & $.34^{* * *}$ \\
\hline & $95 \% \mathrm{CI}$ & $-.44,-.25$ & $-.46,-.27$ & $.24, .44$ \\
\hline \multirow[t]{2}{*}{ Valuing Happiness Factor 1} & $\beta$ & $.17^{* * *}$ & $.20^{* * *}$ & -.06 \\
\hline & $95 \% \mathrm{CI}$ & $.07, .26$ & $.11, .30$ & $-.16, .05$ \\
\hline \multirow[t]{2}{*}{ Valuing Happiness Factor 2} & $\beta$ & -.08 & -.10 & .05 \\
\hline & $95 \% \mathrm{CI}$ & $-.18, .02$ & $-.20,<.01$ & $-.06, .15$ \\
\hline \multirow[t]{2}{*}{ Extraversion } & $\beta$ & $.18^{* * *}$ & $.14^{* *}$ & -.04 \\
\hline & $95 \% \mathrm{CI}$ & $.09, .26$ & $.05, .23$ & $-.13, .05$ \\
\hline Neuroticism & $\beta$ & $-.14^{* *}$ & $-.12^{*}$ & $.22^{* * *}$ \\
\hline
\end{tabular}




\begin{tabular}{cccc}
\hline Value & Life Satisfaction & Positive Affect & Negative Affect \\
\hline $95 \% \mathrm{CI}$ & $-.24,-.04$ & $-.22,-.02$ & $.12, .32$ \\
\hline
\end{tabular}

Notes. $* p<.05 . * * p<.01 . * * * p<.001 . \mathrm{df}=$ degrees of freedom. $\mathrm{CI}=$ confidence interval. We entered age and gender in the first step (Model 1), Happiness Goal Orientations in the second step (Model 2), Valuing Happiness factors in the third step (Model 3), and extraversion and neuroticism in the fourth step (Model 4). Female participants indicate the reference group. All variables except age and gender are standardized. 
Table 9. Bivariate correlations of Study $2 b$.

\begin{tabular}{lll}
\hline & \multicolumn{1}{c}{$\begin{array}{c}\text { Happiness-Related } \\
\text { Strivings }\end{array}$} & \multicolumn{1}{c}{$\begin{array}{c}\text { Happiness-Related } \\
\text { Concerns }\end{array}$} \\
\hline Happiness-Related Strivings & - & .09 \\
Extraversion & $.16^{*}$ & $-.32 * * *$ \\
Neuroticism & -.08 & $.64 * * *$ \\
Life satisfaction & $.15^{*}$ & $-.41^{* * *}$ \\
Positive affect & $.26^{* * *}$ & $-.31 * * *$ \\
Negative affect & -.02 & $.39 * * *$ \\
Autonomy & .07 & $-.50 * * *$ \\
Environmental mastery & .10 & $-.51 * * *$ \\
Personal growth & $.22 * * *$ & $-.33 * * *$ \\
Positive relations with others & .09 & $-.40 * * *$ \\
Purpose in life & $.19 * *$ & $-.39 * * *$ \\
Self-acceptance & $.24 * * *$ & $-.59 * * *$ \\
Age & -.09 & $-.33 * * *$ \\
Gender & -.03 & -.07
\end{tabular}

Notes. ${ }^{*} p<.05 .{ }^{* *} p<.01 .{ }^{* * *} p<.001$. Female participants were coded with 0 , male participants were coded with 1 . The complete correlation matrix can be found in the online materials:

https://osf.io/dg83m/?view_only=485d5346d5904c90ba3fd21614bd1860 
Table 10. Hierarchical multiple regression results of Study $2 \mathrm{~b}$ for Happiness Goal Orientation dimensions predicting subjective well-being, controlling for age and gender, extraversion, and neuroticism.

\begin{tabular}{|c|c|c|c|c|}
\hline & Value & Life Satisfaction & Positive Affect & Negative Affect \\
\hline Model $1(\mathrm{df}=225)$ & $R^{2}$ & $<.01$ & .02 & .01 \\
\hline \multirow[t]{2}{*}{ Age } & $\beta$ & -.01 & .01 & -.01 \\
\hline & $95 \% \mathrm{CI}$ & $-.01, .01$ & $>-.01, .02$ & $-.02,<.01$ \\
\hline \multirow[t]{2}{*}{ Gender: male } & $\beta$ & -.01 & .01 & .13 \\
\hline & $95 \% \mathrm{CI}$ & $-.32, .30$ & $-.30, .32$ & $-.18, .43$ \\
\hline Model $2(\mathrm{df}=223)$ & $\Delta R^{2}$ & $.27^{* * *}$ & $.18^{* * *}$ & $.14^{* * *}$ \\
\hline \multirow[t]{2}{*}{ Age } & $\beta$ & $-.02^{* * *}$ & $<.01$ & $<.01$ \\
\hline & $95 \% \mathrm{CI}$ & $-.03,-.01$ & $-.01, .01$ & $-.01, .01$ \\
\hline \multirow[t]{2}{*}{ Gender: male } & $\beta$ & -.05 & $<.01$ & .16 \\
\hline & $95 \% \mathrm{CI}$ & $-.31, .22$ & $-.28, .28$ & $-.13, .44$ \\
\hline \multirow[t]{2}{*}{ Happiness-Related Strivings } & $\beta$ & $.17^{* *}$ & $.30^{* * *}$ & -.08 \\
\hline & $95 \% \mathrm{CI}$ & $.05, .28$ & $.18, .42$ & $-.20, .05$ \\
\hline \multirow[t]{2}{*}{ Happiness-Related Concerns } & $\beta$ & $-.53^{* * *}$ & $-.34^{* * *}$ & $.40^{* * *}$ \\
\hline & $95 \% \mathrm{CI}$ & $-.65,-.41$ & $-.47,-.22$ & $.27, .52$ \\
\hline Model $3(\mathrm{df}=221)$ & $\Delta R^{2}$ & $.11^{* * *}$ & $.12^{* * *}$ & $.10^{* * *}$ \\
\hline \multirow[t]{2}{*}{ Age } & $\beta$ & $-.01^{* * *}$ & .01 & $<.01$ \\
\hline & $95 \% \mathrm{CI}$ & $-.02,-.01$ & $>-.01, .02$ & $-.01, .01$ \\
\hline \multirow[t]{2}{*}{ Gender: male } & $\beta$ & -.12 & -.02 & .26 \\
\hline & $95 \% \mathrm{CI}$ & $-.37, .13$ & $-.28, .24$ & $-.02, .53$ \\
\hline \multirow[t]{2}{*}{ Happiness-Related Strivings } & $\beta$ & .07 & $.21^{* * *}$ & .01 \\
\hline & $95 \% \mathrm{CI}$ & $-.04, .18$ & $.09, .32$ & $-.11, .13$ \\
\hline \multirow[t]{2}{*}{ Happiness-Related Concerns } & $\beta$ & $-.24^{* *}$ & -.09 & .11 \\
\hline & $95 \% \mathrm{CI}$ & $-.39,-.10$ & $-.25, .06$ & $-.05, .27$ \\
\hline \multirow[t]{2}{*}{ Extraversion } & $\beta$ & $.21^{* * *}$ & $.31^{* * *}$ & -.12 \\
\hline & $95 \% \mathrm{CI}$ & $.09, .32$ & $.19, .43$ & $-.25,<.01$ \\
\hline \multirow[t]{2}{*}{ Neuroticism } & $\beta$ & $-.32^{* * *}$ & $-.21^{* *}$ & $.37^{* * *}$ \\
\hline & $95 \% \mathrm{CI}$ & $-.47,-.18$ & $-.36,-.06$ & $.21, .53$ \\
\hline
\end{tabular}

Notes. $* p<.05 .{ }^{* *} p<.01 . * * * p<.001 . \mathrm{df}=$ degrees of freedom. $\mathrm{CI}=$ confidence interval. We entered age and gender in the first step (Model 1), Happiness Goal Orientations in the second step (Model 2), and extraversion and neuroticism in the third step (Model 3). Female participants indicate the reference group. All variables except age and gender are standardized. 
Table 11. Hierarchical multiple regression results of Study $2 b$ for Happiness Goal Orientations dimensions predicting psychological well-being, controlling for age and gender, extraversion, and neuroticism.

\begin{tabular}{|c|c|c|c|c|c|c|c|}
\hline & Value & Autonomy & $\begin{array}{c}\text { Environmental } \\
\text { mastery }\end{array}$ & Personal growth & Positive relations & Purpose in life & $\begin{array}{c}\text { Self- } \\
\text { acceptance }\end{array}$ \\
\hline Model $1(\mathrm{df}=222)$ & $R^{2}$ & $.07^{* *}$ & $.05^{* *}$ & .02 & .02 & $<.01$ & .01 \\
\hline \multirow[t]{2}{*}{ Age } & $\beta$ & $.02^{* * *}$ & $.02^{* *}$ & -.01 & .01 & $>-.01$ & .01 \\
\hline & $95 \% \mathrm{CI}$ & $.01, .03$ & $.01, .03$ & $-.02,<.01$ & $>-.01, .02$ & $-.01, .01$ & $>-.01, .02$ \\
\hline \multirow[t]{2}{*}{ Gender: male } & $\beta$ & .21 & .03 & -.26 & -.19 & -.14 & .08 \\
\hline & $95 \% \mathrm{CI}$ & $-.09, .51$ & $-.27, .34$ & $-.57, .04$ & $-.50, .12$ & $-.45, .17$ & $-.23, .39$ \\
\hline Model $2(\mathrm{df}=220)$ & $\Delta R^{2}$ & $.21^{* * *}$ & $.27^{* * *}$ & $.21^{* * *}$ & $.19^{* * *}$ & $.23^{* * *}$ & $.45^{* * *}$ \\
\hline \multirow[t]{2}{*}{ Age } & $\beta$ & .01 & .01 & $-.01^{* *}$ & $>-.01$ & $-.01^{*}$ & -.01 \\
\hline & $95 \% \mathrm{CI}$ & $>-.01, .02$ & $>-.01, .01$ & $-.02,-.01$ & $-.01, .01$ & $-.02,>-.01$ & $-.01,>.01$ \\
\hline \multirow[t]{2}{*}{ Gender: male } & $\beta$ & .17 & -.01 & $-.29^{*}$ & -.23 & -.17 & .03 \\
\hline & $95 \% \mathrm{CI}$ & $-.10, .44$ & $-.27, .25$ & $-.56,-.01$ & $-.51, .05$ & $-.44, .10$ & $-.20, .26$ \\
\hline \multirow[t]{2}{*}{ Happiness-Related Strivings } & $\beta$ & $.15^{*}$ & $.19^{* *}$ & $.26^{* * *}$ & $.14^{*}$ & $.22^{* * *}$ & $.31^{* * *}$ \\
\hline & $95 \% \mathrm{CI}$ & $.03, .26$ & $.08, .30$ & $.14, .37$ & $.02, .26$ & $.10, .33$ & $.22, .41$ \\
\hline \multirow[t]{2}{*}{ Happiness-Related Concerns } & $\beta$ & $-.46^{* * *}$ & $-.52^{* * *}$ & $-.42^{* * *}$ & $-.45^{* * *}$ & $-.47^{* * *}$ & $-.65^{* * *}$ \\
\hline & $95 \% \mathrm{CI}$ & $-.58,-.34$ & $-.64,-.41$ & $-.54,-.30$ & $-.57,-.32$ & $-.59,-.35$ & $-.75,-.54$ \\
\hline Model $3(\mathrm{df}=218)$ & $\Delta R^{2}$ & $.08^{* * *}$ & $.13^{* * *}$ & .02 & $.06^{* * *}$ & $.14^{* * *}$ & $.16^{* * *}$ \\
\hline \multirow[t]{2}{*}{ Age } & $\beta$ & $.01^{*}$ & .01 & $-.01^{* *}$ & $>-.01$ & -.01 & $>-.01$ \\
\hline & $95 \% \mathrm{CI}$ & $<.01, .02$ & $>-.01, .02$ & $-.02,>-.01$ & $-.01, .01$ & $-.01,<.01$ & $-.01,<.01$ \\
\hline \multirow[t]{2}{*}{ Gender: male } & $\beta$ & .08 & -.09 & -.27 & $-.28^{*}$ & -.14 & -.04 \\
\hline & $95 \% \mathrm{CI}$ & $-.18, .34$ & $-.33, .15$ & $-.54, .01$ & $-.56,-.01$ & $-.40, .12$ & $-.24, .16$ \\
\hline \multirow[t]{2}{*}{ Happiness-Related Strivings } & $\beta$ & .07 & .08 & $.23^{* * *}$ & .07 & $.13^{*}$ & $.20^{* * *}$ \\
\hline & $95 \% \mathrm{CI}$ & $-.04, .18$ & $-.02, .18$ & $.11, .35$ & $-.05, .19$ & $.02, .24$ & $.11, .29$ \\
\hline \multirow[t]{2}{*}{ Happiness-Related Concerns } & $\beta$ & $-.21^{* *}$ & $-.20^{* *}$ & $-.36^{* * *}$ & $-.24^{* *}$ & $-.28^{* * *}$ & $-.31^{* * *}$ \\
\hline & $95 \% \mathrm{CI}$ & $-.36,-.06$ & $-.34,-.07$ & $-.53,-.20$ & $-.40,-.08$ & $-.43,-.13$ & $-.43,-.19$ \\
\hline Extraversion & $\beta$ & $.12^{*}$ & $.23^{* * *}$ & $.15^{*}$ & $.15^{*}$ & $.39^{* * *}$ & $.28^{* * *}$ \\
\hline
\end{tabular}




\begin{tabular}{ccccccc}
\hline & Value & Autonomy & $\begin{array}{c}\text { Environmental } \\
\text { mastery }\end{array}$ & Personal growth Positive relations & Purpose in life \\
acceptance
\end{tabular}

Notes. $* p<.05 . * * p<.01 . * * * p<.001 . \mathrm{df}=$ degrees of freedom. $\mathrm{CI}=$ confidence interval. We entered age and gender in the first step (Model 1), Happiness Goal Orientations in the second step (Model 2), and extraversion and neuroticism in the third step (Model 3). Female participants indicate the reference group. All variables except age and gender are standardized. 
Table 12. Descriptive statistics and Cronbach's alphas of Study 3.

\begin{tabular}{|c|c|c|c|}
\hline Scale & $M$ & $S D$ & $\alpha$ \\
\hline \multicolumn{4}{|l|}{ Happiness Goal Orientations } \\
\hline Happiness-Related Strivings & 3.07 & 0.76 & .78 \\
\hline Happiness-Related Concerns & 3.08 & 1.10 & .89 \\
\hline \multicolumn{4}{|l|}{ Lay Definitions of Happiness } \\
\hline Positive attitude & 4.82 & 0.92 & .76 \\
\hline Tranquility & 4.73 & 0.97 & .74 \\
\hline Joy and desires & 4.42 & 0.89 & .71 \\
\hline Absence of negativity & 4.01 & 1.26 & .83 \\
\hline Personal development & 4.43 & 0.99 & .72 \\
\hline Purpose & 4.18 & 1.08 & .72 \\
\hline Belonging & 4.67 & 1.09 & .84 \\
\hline Luck & 3.78 & 1.32 & .87 \\
\hline \multicolumn{4}{|l|}{ Intentions to pursue Happiness } \\
\hline Positive attitude & 4.49 & 1.02 & .81 \\
\hline Tranquility & 4.56 & 0.91 & .76 \\
\hline Joy and desires & 4.43 & 0.84 & .63 \\
\hline Absence of negativity & 3.73 & 1.05 & .64 \\
\hline Personal development & 4.59 & 0.94 & .71 \\
\hline Purpose & 4.09 & 1.02 & .67 \\
\hline Belonging & 4.35 & 1.04 & .78 \\
\hline Luck & 3.32 & 1.23 & .81 \\
\hline \multicolumn{4}{|l|}{ Beliefs About Well-Being } \\
\hline Experience of pleasure & 4.04 & 0.65 & .74 \\
\hline Avoidance of negative experiences & 2.47 & 1.10 & .94 \\
\hline Self-Development & 3.92 & 0.69 & .74 \\
\hline Contribution to others & 3.41 & 0.86 & .84 \\
\hline \multicolumn{4}{|l|}{ Orientations to Happiness } \\
\hline Pleasure & 3.40 & 0.65 & .67 \\
\hline Engagement & 2.87 & 0.63 & .61 \\
\hline Meaning & 2.78 & 0.77 & .76 \\
\hline Extraversion & 2.91 & 0.83 & .61 \\
\hline Neuroticism & 3.22 & 0.96 & .74 \\
\hline Life satisfaction & 3.26 & 0.95 & .86 \\
\hline Positive affect & 3.46 & 0.75 & .90 \\
\hline Negative affect & 2.70 & 0.80 & .85 \\
\hline Autonomy & 3.63 & 0.84 & .66 \\
\hline Environmental mastery & 3.55 & 0.79 & .57 \\
\hline Personal growth & 4.16 & 0.71 & .65 \\
\hline Positive relations with others & 3.56 & 0.91 & .57 \\
\hline Purpose in life & 3.87 & 0.69 & .33 \\
\hline Self-acceptance & 3.51 & 0.98 & .78 \\
\hline
\end{tabular}


Table 13. Bivariate correlations of Study 3.

\begin{tabular}{|c|c|c|}
\hline & $\begin{array}{c}\text { Happiness-Related } \\
\text { Strivings }\end{array}$ & $\begin{array}{c}\text { Happiness-Related } \\
\text { Concerns }\end{array}$ \\
\hline Happiness-Related Strivings & - & $.18^{* *}$ \\
\hline \multicolumn{3}{|l|}{ Lay Definitions of Happiness } \\
\hline Positive attitude & $.14^{*}$ & -.04 \\
\hline Tranquility & $.17 * *$ & -.01 \\
\hline Joy and desires & $.17 * *$ & .09 \\
\hline Absence of negativity & .10 & $.26 * * *$ \\
\hline Personal development & $.21 * * *$ & -.11 \\
\hline Purpose & $.20 * * *$ & .09 \\
\hline Belonging & .03 & -.01 \\
\hline Luck & .07 & .10 \\
\hline \multicolumn{3}{|l|}{ Intentions to pursue Happiness } \\
\hline Positive attitude & $.27 * * *$ & $-.45 * * *$ \\
\hline Tranquility & $.23 * * *$ & $-.27 * * *$ \\
\hline Joy and desires & $.23 * * *$ & $-.18 * *$ \\
\hline Absence of negativity & $.23 * * *$ & .03 \\
\hline Personal development & $.24 * * *$ & $-.26 * * *$ \\
\hline Purpose & $.40 * * *$ & -.09 \\
\hline Belonging & .11 & $-.14 *$ \\
\hline Luck & $.26 * * *$ & -.02 \\
\hline \multicolumn{3}{|l|}{ Beliefs About Well-Being } \\
\hline Experience of pleasure & .08 & .03 \\
\hline Avoidance of negative experiences & .11 & $.24 * * *$ \\
\hline Self-Development & $.17 * *$ & -.03 \\
\hline Contribution to others & $.12 *$ & $-.15^{*}$ \\
\hline \multicolumn{3}{|l|}{ Orientations to Happiness } \\
\hline Pleasure & $.30 * * *$ & -.04 \\
\hline Engagement & $.22 * * *$ & $-.30 * * *$ \\
\hline Meaning & $.17 * *$ & -.08 \\
\hline Extraversion & $.13 *$ & $-.37 * * *$ \\
\hline Neuroticism & .01 & $.73 * * *$ \\
\hline Life satisfaction & .12 & $-.48 * * *$ \\
\hline Positive affect & .12 & $-.51 * * *$ \\
\hline Negative affect & -.03 & $.64 * * *$ \\
\hline Autonomy & .09 & $-.40 * * *$ \\
\hline Environmental mastery & -.01 & $-.62 * * *$ \\
\hline Personal growth & $.17 * *$ & $-.32 * * *$ \\
\hline Positive relations with others & .08 & $-.28 * * *$ \\
\hline Purpose in life & $>-.01$ & $-.22 * * *$ \\
\hline Self-acceptance & .05 & $-.56 * * *$ \\
\hline Age & -.11 & $-.24 * * *$ \\
\hline Gender & .08 & $-.18 * * *$ \\
\hline
\end{tabular}

Notes. ${ }^{*} p<.05 . * * p<.01 . * * * p<.001$. Female participants were coded with 0 , male participants were coded with 1 . The complete correlation matrix can be found in the online materials: https://osf.io/dg83m/?view only=485d5346d5904c90ba3fd21614bd1860 
Table 14. Hierarchical multiple regression results of Study 3 for Happiness Goal Orientation dimensions predicting subjective well-being, controlling for age and gender, extraversion, and neuroticism.

\begin{tabular}{|c|c|c|c|c|}
\hline & Value & Life Satisfaction & Positive Affect & Negative Affect \\
\hline Model $1(\mathrm{df}=274)$ & $R^{2}$ & $<.01$ & .01 & $.04^{* *}$ \\
\hline \multirow[t]{2}{*}{ Age } & $\beta$ & -.01 & $>-.01$ & $>-.01$ \\
\hline & $95 \% \mathrm{CI}$ & $-.02,<.01$ & $-.02, .01$ & $-.01, .01$ \\
\hline \multirow[t]{2}{*}{ Gender: male } & $\beta$ & .03 & .23 & $-.51^{* *}$ \\
\hline & $95 \% \mathrm{CI}$ & $-.31, .37$ & $-.10, .57$ & $-.85,-.18$ \\
\hline Model $2(\mathrm{df}=272)$ & $\Delta R^{2}$ & $.30^{* * *}$ & $.32^{* * *}$ & $.40^{* * *}$ \\
\hline \multirow[t]{2}{*}{ Age } & $\beta$ & $-.02^{* *}$ & $-.01^{*}$ & .01 \\
\hline & $95 \% \mathrm{CI}$ & $-.03,-.01$ & $-.03,>-.01$ & $>-.01, .02$ \\
\hline \multirow[t]{2}{*}{ Gender: male } & $\beta$ & -.26 & -.06 & -.21 \\
\hline & $95 \% \mathrm{CI}$ & $-.54, .03$ & $-.34, .23$ & $-.47, .04$ \\
\hline \multirow[t]{2}{*}{ Happiness-Related Strivings } & $\beta$ & $.21^{* * *}$ & $.21^{* * *}$ & $-.14^{* *}$ \\
\hline & $95 \% \mathrm{CI}$ & $.11, .31$ & $.11, .31$ & $-.23,-.05$ \\
\hline \multirow[t]{2}{*}{ Happiness-Related Concerns } & $\beta$ & $-.57^{* * *}$ & $-.58^{* * *}$ & $.67^{* * *}$ \\
\hline & $95 \% \mathrm{CI}$ & $-.68,-.47$ & $-.69,-.48$ & $.58, .76$ \\
\hline Model $3(\mathrm{df}=270)$ & $\Delta R^{2}$ & $.10^{* * *}$ & $.13^{* * *}$ & $.13^{* * *}$ \\
\hline \multirow[t]{2}{*}{ Age } & $\beta$ & -.01 & $>-.01$ & $>-.01$ \\
\hline & $95 \% \mathrm{CI}$ & $-.02,<.01$ & $-.02, .01$ & $-.01, .01$ \\
\hline \multirow[t]{2}{*}{ Gender: male } & $\beta$ & $-.40^{* *}$ & -.22 & -.04 \\
\hline & $95 \% \mathrm{CI}$ & $-.67,-.13$ & $-.48, .04$ & $-.26, .19$ \\
\hline \multirow[t]{2}{*}{ Happiness-Related Strivings } & $\beta$ & $.14^{* *}$ & $.14^{* *}$ & -.07 \\
\hline & $95 \% \mathrm{CI}$ & $.05, .24$ & $.05, .23$ & $-.15, .01$ \\
\hline \multirow[t]{2}{*}{ Happiness-Related Concerns } & $\beta$ & $-.18^{*}$ & $-.14^{*}$ & $.23^{* * *}$ \\
\hline & $95 \% \mathrm{CI}$ & $-.33,-.03$ & $-.29,>-.01$ & $.11, .36$ \\
\hline \multirow[t]{2}{*}{ Extraversion } & $\beta$ & .10 & $.11^{*}$ & -.04 \\
\hline & $95 \% \mathrm{CI}$ & $>-.01, .20$ & $.01, .21$ & $-.13, .04$ \\
\hline \multirow[t]{2}{*}{ Neuroticism } & $\beta$ & $-.45^{* * *}$ & $-.52^{* * *}$ & $.55^{* * *}$ \\
\hline & $95 \% \mathrm{CI}$ & $-.60,-.31$ & $-.65,-.38$ & $.43, .67$ \\
\hline
\end{tabular}

Notes. $* p<.05 . * * p<.01 . * * * p<.001 . \mathrm{df}=$ degrees of freedom. $\mathrm{CI}=$ confidence interval. We entered age and gender in the first step (Model 1), Happiness Goal Orientations in the second step (Model 2), and extraversion and neuroticism in the third step (Model 3). Female participants indicate the reference group. All variables except age and gender are standardized. 
Table 15. Hierarchical multiple regression results of Study 3 for Happiness Goal Orientations dimensions predicting psychological wellbeing, controlling for age and gender, extraversion, and neuroticism.

\begin{tabular}{|c|c|c|c|c|c|c|c|}
\hline & Value & Autonomy & $\begin{array}{l}\text { Environmental } \\
\text { mastery }\end{array}$ & Personal growth & Positive relations & Purpose in life & Self-acceptance \\
\hline Model $1(\mathrm{df}=274)$ & $R^{2}$ & $.06^{* * *}$ & .01 & .01 & $<.01$ & $<.01$ & $<.01$ \\
\hline \multirow{2}{*}{ Age } & $\beta$ & $.03^{* *}$ & $<.01$ & -.01 & $>-.01$ & $<.01$ & $<.01$ \\
\hline & $95 \% \mathrm{CI}$ & $.01, .04$ & $-.01, .02$ & $-.02, .01$ & $-.02, .01$ & $-.02, .02$ & $-.01, .02$ \\
\hline \multirow[t]{2}{*}{ Gender: male } & $\beta$ & .32 & .25 & .24 & -.18 & .02 & .14 \\
\hline & $95 \% \mathrm{CI}$ & $-.01, .65$ & $-.09, .59$ & $-.10, .57$ & $-.52, .16$ & $-.32, .36$ & $-.19, .48$ \\
\hline Model $2(\mathrm{df}=272)$ & $\Delta R^{2}$ & $.14^{* * *}$ & $.40^{* * *}$ & $.16^{* * *}$ & $.11^{* * *}$ & $.05^{* * *}$ & $.35^{* * *}$ \\
\hline \multirow[t]{2}{*}{ Age } & $\beta$ & $.02^{*}$ & -.01 & -.01 & -.01 & -.01 & -.01 \\
\hline & $95 \% \mathrm{CI}$ & $<.01, .03$ & $-.02,<.01$ & $-.03,<.01$ & $-.02, .01$ & $-.02, .01$ & $-.03,<.01$ \\
\hline \multirow[t]{2}{*}{ Gender: male } & $\beta$ & .12 & -.04 & .02 & $-.36^{*}$ & -.08 & -.14 \\
\hline & $95 \% \mathrm{CI}$ & $-.19, .43$ & $-.31, .23$ & $-.30, .33$ & $-.68,-.03$ & $-.42, .26$ & $-.42, .14$ \\
\hline \multirow[t]{2}{*}{ Happiness-Related Strivings } & $\beta$ & $.17^{* *}$ & $.11^{*}$ & $.24^{* * *}$ & $.14^{*}$ & .04 & $.16^{* *}$ \\
\hline & $95 \% \mathrm{CI}$ & $.06, .28$ & $.01, .20$ & $.12, .35$ & $.03, .26$ & $-.08, .16$ & $.06, .26$ \\
\hline \multirow[t]{2}{*}{ Happiness-Related Concerns } & $\beta$ & $-.39^{* * *}$ & $-.66^{* * *}$ & $-.39^{* * *}$ & $-.34^{* * *}$ & $-.24^{* * *}$ & $-.62^{* * *}$ \\
\hline & $95 \% \mathrm{CI}$ & $-.51,-.28$ & $-.76,-.57$ & $-.50,-.27$ & $-.46,-.23$ & $-.36,-.12$ & $-.72,-.52$ \\
\hline Model $3(\mathrm{df}=270)$ & $\Delta R^{2}$ & $.04^{* * *}$ & $.08^{* * *}$ & .01 & $.07^{* * *}$ & .00 & $.07^{* * *}$ \\
\hline \multirow[t]{2}{*}{ Age } & $\beta$ & $.02^{* *}$ & $>-.01$ & -.01 & $>-.01$ & -.01 & -.01 \\
\hline & $95 \% \mathrm{CI}$ & $.01, .04$ & $-.02, .01$ & $-.02, .01$ & $-.02, .01$ & $-.02, .01$ & $-.02, .01$ \\
\hline \multirow[t]{2}{*}{ Gender: male } & $\beta$ & .03 & -.13 & -.04 & $-.46^{* *}$ & -.07 & -.26 \\
\hline & $95 \% \mathrm{CI}$ & $-.28, .34$ & $-.39, .12$ & $-.36, .28$ & $-.77,-.14$ & $-.41, .27$ & $-.53,<.01$ \\
\hline \multirow[t]{2}{*}{ Happiness-Related Strivings } & $\beta$ & $.12^{*}$ & .04 & $.21^{* * *}$ & .08 & .05 & $.10^{*}$ \\
\hline & $95 \% \mathrm{CI}$ & $.01, .23$ & $-.06, .13$ & $.10, .33$ & $-.04, .19$ & $-.08, .17$ & $.01, .20$ \\
\hline \multirow[t]{2}{*}{ Happiness-Related Concerns } & $\beta$ & -.15 & $-.34^{* * *}$ & $-.25^{* *}$ & -.02 & $-.28^{* *}$ & $-.30^{* * *}$ \\
\hline & $95 \% \mathrm{CI}$ & $-.32, .02$ & $-.48,-.20$ & $-.43,-.08$ & $-.20, .15$ & $-.47,-.09$ & $-.45,-.15$ \\
\hline \multirow[t]{2}{*}{ Extraversion } & $\beta$ & .09 & $.20^{* * *}$ & .02 & $.18^{* *}$ & -.02 & .08 \\
\hline & $95 \% \mathrm{CI}$ & $-.02, .21$ & $.10, .29$ & $-.10, .14$ & $.06, .30$ & $-.15, .11$ & $-.02, .18$ \\
\hline
\end{tabular}




\begin{tabular}{|c|c|c|c|c|c|c|c|}
\hline & Value & Autonomy & $\begin{array}{c}\text { Environmental } \\
\text { mastery }\end{array}$ & Personal growth & Positive relations & Purpose in life & Self-acceptance \\
\hline \multirow[t]{2}{*}{ Neuroticism } & $\beta$ & $-.27^{* * *}$ & $-.31^{* * *}$ & -.16 & $-.32^{* * *}$ & .04 & $-.38^{* * *}$ \\
\hline & $95 \% \mathrm{CI}$ & $-.43,-.11$ & $-.44,-.18$ & $-.33,<.01$ & $-.49,-.16$ & $-.14, .22$ & $-.52,-.24$ \\
\hline
\end{tabular}

Notes. $* p<.05 . * * p<.01 . * * * p<.001 . \mathrm{df}=$ degrees of freedom. $\mathrm{CI}=$ confidence interval. We entered age and gender in the first step (Model 1), Happiness Goal Orientations in the second step (Model 2), and extraversion and neuroticism in the third step (Model 3). Female participants indicate the reference group. All variables except age and gender are standardize 